\title{
Capítulo 4 \\ Las víctimas de la región de Montes de María
}

\author{
María del Mar Martínez* \\ Camilo Andrés Castiblanco**
}

* Socióloga y comunicadora Social de la Universidad Santo Tomás.

** Sociólogo. Con Maestría en Sociología de la Universidad Nacional de Colombia. 



\section{Introducción}

La complejidad de la violencia en la región, analizada en el capítulo anterior, se tradujo en distintas formas de afectación a la población civil y contra miembros de las Fuerza Pública, así como en intensificaciones diferenciadas de los repertorios de la violencia en contra de la sociedad en general. De esa manera, el calificativo de víctima de la violencia - de la región de los Montes de María- es una abstracción jurídica (devenida de la Ley 1448 de 2011), pública (en el sentido de los informes del Centro Nacional de Memoria Histórica) y académica, que esconde distintas manifestaciones concretas de dicha condición. El término es fundamental para poner de presente - como denuncia - a una población que se vio afectada por la irregularidad del conflicto; y para generar algunas limitantes conceptuales provenientes del Derecho Internacional Humanitario; pero también esconde la particularidad y heterogeneidad de los grupos que llevan, desafortunadamente, este moquete, y de los propósitos que llevaron a que los grupos armados se ensañasen contra esta población.

En los trabajos de Baer (2003) y de Girón y Vidales (2010) se hace hincapié en la necesidad imperiosa de dotar de humanidad a estas víctimas, ya que solo desde ese espacio es posible que la sociedad genere procesos de empatía con esta población y comprenda la magnitud de la tragedia vivida. Pero también porque es el mecanismo para denunciar a los victimarios (en términos de memoria o en términos judiciales), generando una lectura lógica según la cual siempre que se hable de una víctima hay, necesariamente, que determinar la existencia de uno o varios victimarios.

Esta manera de entender a las víctimas de la región de los Montes de María significa generar una ruptura epistemológica: estos no son solamente un objeto de estudio, sino sujetos que asumen 
el protagonismo en el recuento de las acciones y en el análisis de la información. Esto implica que la interpretación final de los datos estadísticos de los que partirá este capítulo está en las interpretaciones que las poblaciones y las víctimas hacen de lo acontecido; por ello, el capítulo iniciará con una recopilación de la información estadística sobre los hechos victimizantes en la región, pero inmediatamente se cualificará y apoyará en el trabajo de campo desarrollado por el equipo de investigación 1 .

Este ejercicio en el territorio permitió contrastar la información enunciada en los capítulos anteriores de esta publicación: la violencia no tuvo las mismas intensidades ni repertorios en la región; al interior de esta misma se presentaron distintas manifestaciones de la violencia. Por ello, se hizo necesario desarrollar un abordaje en el que se dimensionaran las lógicas territoriales y relaciones de poder en el espacio de los actores irregulares (Salas, 2014).

\section{Las dinámicas de la victimización en la región de Montes de María. Un abordaje desde las cifras y las estadísticas}

Para la elaboración de este apartado se tuvieron en consideración distintos tipos de fuentes (académicas, oficiales y sociales) las cuales dimensionaron de manera diferenciada los procesos de violencia ocurridos en la región. Con el propósito de analizar contextualmente estas cifras, se inicia con un abordaje panorámico del fenómeno en la región, en el que se pueda comprender cuáles son los momentos de mayor violencia y los territorios que presentan mayor afectación por acciones violentas irregulares. A partir de estos datos generales, se puede iniciar un proceso de profundización en fenómenos particulares derivados de dichas fuentes iniciales.

La primera mirada contextual tiene que ver con una descripción del número de acciones violentas que se produjeron en cada uno de los municipios de la región, en un periodo comprendido entre 1985 y el 2012, tomando como fuentes principales al Cinep, al cNMH, la base

1 Trabajo de campo desarrollado entre los meses de noviembre de 2017 y febrero de 2018, en diversos municipios y corregimientos de la región Montes de María. 
de datos del periódico El Tiempo y la Revista Semana, y la información de archivo suministrada por la Armada Nacional de Colombia ${ }^{2}$.

Figura IV-1: Relación de tipo de delitos por municipio

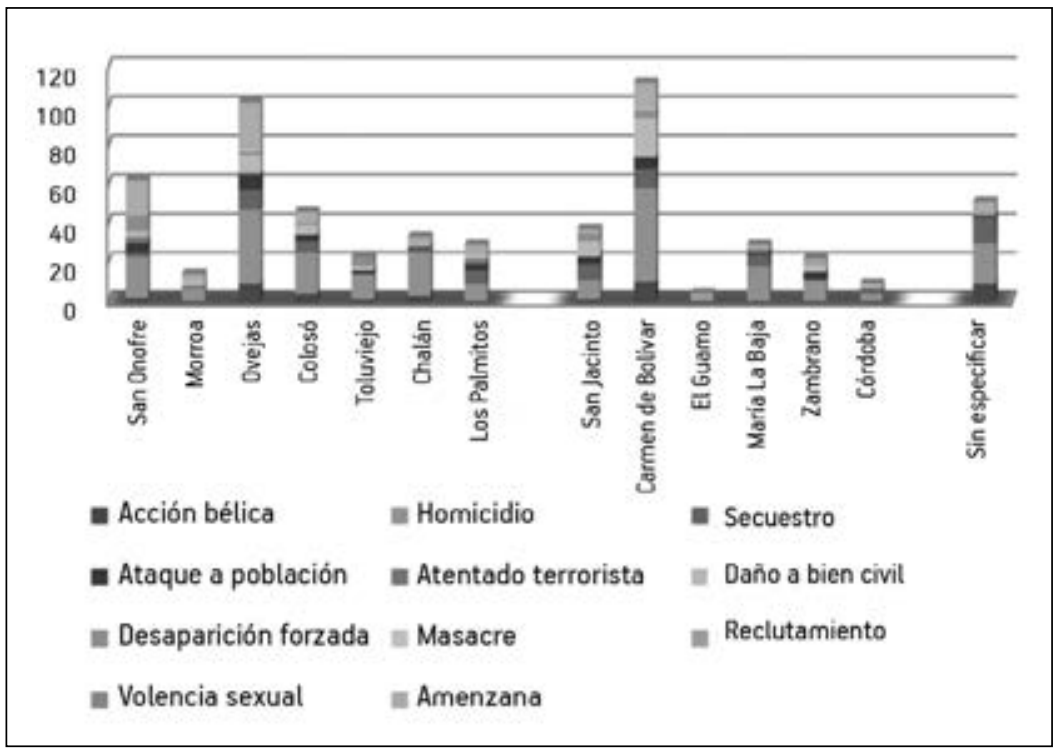

Fuente: elaboración propia (2017). Tomado de Base de datos Noche y Niebla; Observatorio de Conflicto y Memoria del CNMH, UARIV y archivo digital del periódico El Tiempo y Revista Semana.

Un primer elemento que vale la pena poner de presente es la composición de municipios heterogéneos que hacen parte de los Montes de María; algunos de ellos han sido incluidos en los abordajes sobre la violencia en la región aunque no hagan parte de la cadena montañosa que conecta a María la Baja con la zona conocida como María la Alta, pero que por las dinámicas de la violencia se entrecruza con este territorio, como es el caso del municipio de Ovejas. Al hacer los primeros abordajes territoriales de la violencia, empezó a ser evidente

2 Vale la pena señalar que las categorías con las que se discriminó la información corresponden a las de la Base de Datos Noche y Niebla, contenidos en el Marco Conceptual del Banco de datos de Derechos Humanos y Violencia Política (Cinep, 2008), que a su vez son retomados por el Centro Nacional de Memoria Histórica para el análisis de la información del Observatorio de Memoria y Conflicto. 
que la intensidad de las acciones armadas no era la misma a lo largo del territorio, y que era necesario establecer análisis particulares por municipio3.

En la revisión realizada se pone de presente la distribución de la violencia por toda la región, afectando a todos los municipios que la componen. Esta situación se sustenta en la omnipresencia de los grupos armados ilegales en todos los municipios, ya que la infraestructura de intercomunicación, las rutas, y los recursos en disputa atravesaban el territorio. El entrecruzamiento de estos recursos y la interconexión de actores, redes y estructuras de poder hacen que la región en su conjunto padezca la violencia, aunque con diferencias claras y bien marcadas (De los Ríos, Becerra y Oyaga - Equipo ILSA, 2012).

La anterior figura pone de presente la concentración de la violencia en tres municipios: San Onofre, Ovejas y Carmen de Bolívar. Tres municipios que están interrelacionados porque son el punto de entrada a la región desde la zona ganadera de Córdoba y Sucre, y porque conectan con la zona marítima de Tolú, Coveñas y San Bernardo del Viento, municipios que han tenido distintas configuraciones en las economías ilegales que se han dado en esta zona. El informe del Observatorio del Programa Presidencial de Derechos Humanos y Derecho Internacional Humanitario "Panorama actual de la región de los Montes de María y su entorno" (2003) da una explicación sintética de esta situación:

en este territorio se asentaron las primeras estructuras guerrilleras en la década de los ochenta, y fue la zona en la que se consolidó la presencia de las FARC en la década del noventa, lo cual marcó una fuerte reacción por parte de los grupos de Autodefensa, quienes asumieron que había una relación entre la población civil y estos grupos ilegales. (p. 57)

De esa manera, estos tres municipios son arquetípicos de un fenómeno que tiende a ser común en toda la región: la alternancia en el control ilegal del territorio entre los grupos armados ilegales; lo cual va a hacer que estos tomen a la población civil como objetivo

3 La categoría "sin especificar" corresponde a las fuentes en las que se señala que las acciones violentas ocurrieron en la región de los Montes de María, sin especificar con puntualidad el municipio, vacío informativo que está presente en las notas de prensa consultadas. 
de guerra, acusándoles de ser colaboradores o auspiciadores de las contrapartes. Esta estigmatización por parte de los actores armados ilegales sobre la población civil va a ser uno de los ejes explicativos utilizados por varios estudios para explicar el uso de la barbarie y el terror como estrategia de guerra, en los que se pone de presente que el intento de dicha alternancia genera una gran condición de vulnerabilidad para la población civil.

La misma figura que se presenta a continuación es ilustrativa sobre la distribución de las acciones violentas que se cometieron contra la población y que generaron víctimas tanto civiles como militares. De nuevo, debe señalarse que estas categorías son abstracciones utilizadas para sistematizar la información, pero que como se verá más adelante (en el análisis cualitativo y en las crónicas periodísticas) se configuran de manera distinta según el territorioy la intencionalidad del victimario.

En los repertorios de la violencia de los actores armados ilegales en la región de los Montes de María se desplegaron principalmente acciones violentas en contra de la población civil. Según el informe La Tierra en Disputa (CNMH, 2010), los combates entre los actores irregulares o entre estos y la Fuerza Pública son menores en comparación de las acciones violentas contra los civiles, lo cual da cuenta de que el elevado número de víctimas no corresponde a un efecto colateral de las acciones bélicas, sino a iniciativas planeadas y diseñadas para atentar directamente contra la población civil.

Un segundo elemento panorámico que permite comprender la situación vivida en la región es la distribución de las acciones violentas por año, información que permite dimensionar las coyunturas más críticas y que generaron mayor afectación sobre la población civil y mayor número de víctimas civiles y militares.

Los primeros grupos en hacer presencia en la región fueron las distintas estructuras guerrilleras, pequeñas estructuras ilegales que entraron a la región desde la década de los años setenta, intentando generar relaciones con las organizaciones campesinas preexistentes, sin lograr los resultados esperados. Esta situación va a generar procesos de violencia contra la población, en un hecho que marcará una distancia entre la población y estos grupos. La siguiente tabla da cuenta de la presencia de estas primeras organizaciones guerrilleras en el territorio, y el número de acciones violentas de las que se le responsabiliza. 
Figura IV-2: Acciones violentas por categoría (1985-2014)

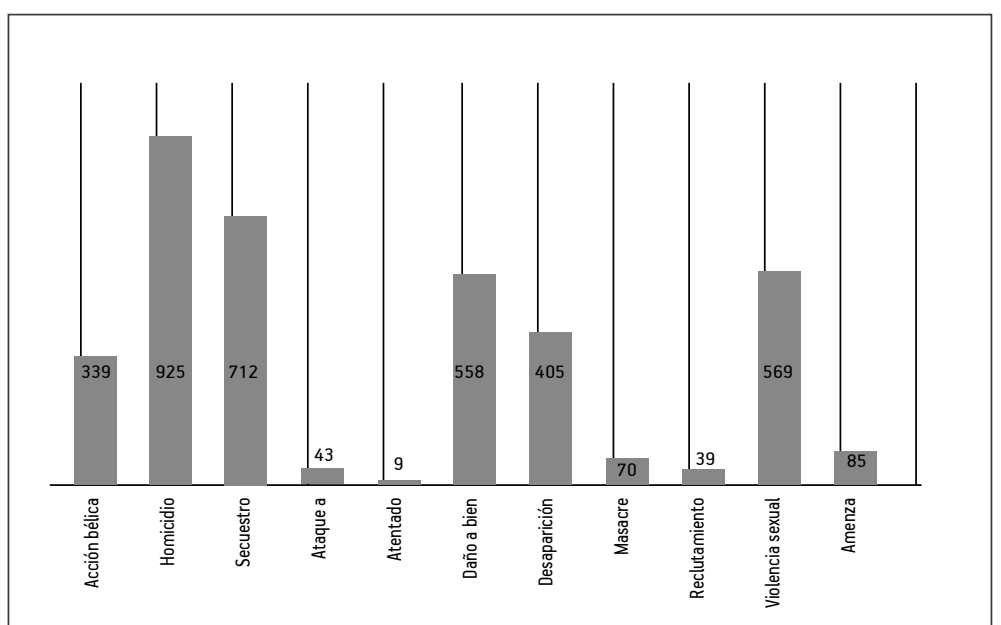

Fuente: elaboración propia (2017). Tomado de Base de datos Noche y Niebla; Observatorio de Conflicto y Memoria del CNMH, UARIV y archivo digital del periódico El Tiempo y de la Revista Semana.

La tabla IV-1 evidencia los distintos periodos de incidencia de las distintas estructuras guerrilleras y su capacidad real de afectación sobre la población y la infraestructura civil; siendo las FARC y el ELN 4 las que mayor presencia tienen yquienes mayor afectación generaron.

También pone de presente los picos de la violencia guerrillera, los cuales podrían ubicarse en el periodo de tiempo comprendido entre 1996 y 2003, un periodo que inicia con el proceso de consolidación de las FARC en la región, lo que le significa unas tensiones y disputas con otras estructuras guerrilleras y con la Fuerza Pública; y que después se agrava considerablemente con los enfrentamientos con las AUC que se van a dar a finales de la década de los años noventa.

4 La categoría "guerrilla no identificada" corresponde a los testimonios en los que se adjudica la responsabilidad del hecho a la "guerrilla", sin especificar a cuál de los diversos grupos corresponde. Sin embargo, por extrapolación de los datos se puede repartir proporcionalmente este número de casos entre los otros grupos armados, haciendo más incidente la presencia de las FARC y el ELN en la región. 


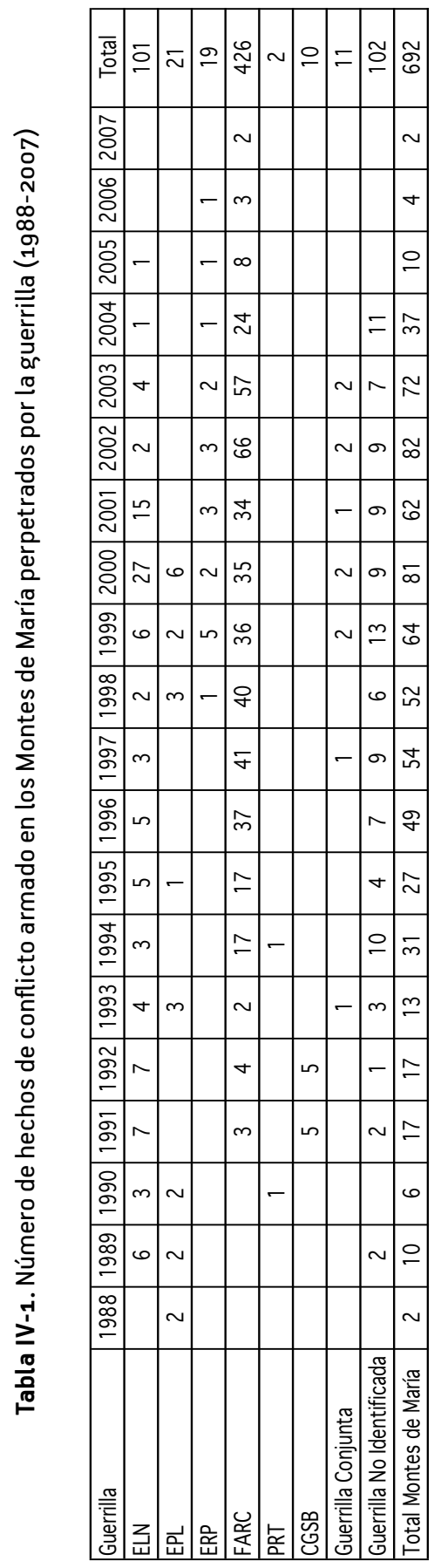

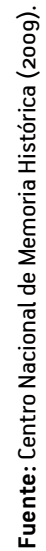


La capacidad de afectación de las FARc está presente en todas las categorías de violencia, sin embargo, tienen una alta responsabilidad en dos hechos victimizantes específicos: por un lado, los esfuerzos de financiación de sus estructuras ilegales a través de la extorsión y el secuestro a ganaderos, palmicultores, hacendados y medianos comerciantes; $y$, por otro lado, el uso de artefactos explosivos no convencionales - minas antipersonales y otros medios prohibidos por el DIH, como los artefactos explosivos improvisados, con los que van a generar un gran número de víctimas en la región, civiles y militares-, fenómenos que no siempre se parametrizaron de manera adecuada, y sobre los que aún hay interrogantes respecto a la magnitud de estos delitos; sobre todo si se tiene en cuenta que algunos centros de investigación se concentran en las acciones bélicas o en los casos que pueden ser registrados de forma objetiva, desconociendo o invisibilizando otras manifestaciones de violencia.

Casos como el burro bomba en el municipio de Chalán (Sucre), o los diversos testimonios de miembros de la Fuerza Pública afectados por explosivos improvisados, dan cuenta de esta situación que afectó por igual a la población civil (CNMH, 2009) y a los miembros de las instituciones militares (Castiblanco et al., 2017). Sin embargo, la presencia de "campos minados" en el territorio genera dinámicas de victimización que van más allá del número de heridos o muertos por la acción directa de las minas; estos campos generan procesos de confinamiento, terror, dificultades de movilidad e incomunicación con los centros urbanos.

Así mismo, como lo recoge el Centro Nacional de Memoria Histórica, el accionar de este grupo armado ilegal está marcado por una constante presencia de acciones irregulares, lo cual va a determinar una infracción permanente al DIH, y a las regulaciones normativas que limitan el comportamiento de los combatientes. Así lo evidencia la siguiente tabla5:

5 El CNMH se limita a parametrizar la información en la que los grupos armados generan acciones bélicas, una mirada más amplia debe recoger afectaciones no bélicas, tales como la extorsión, las amenazas y otras acciones irregulares contra la población civil que no necesariamente impliquen la comisión de un hecho bélico. 

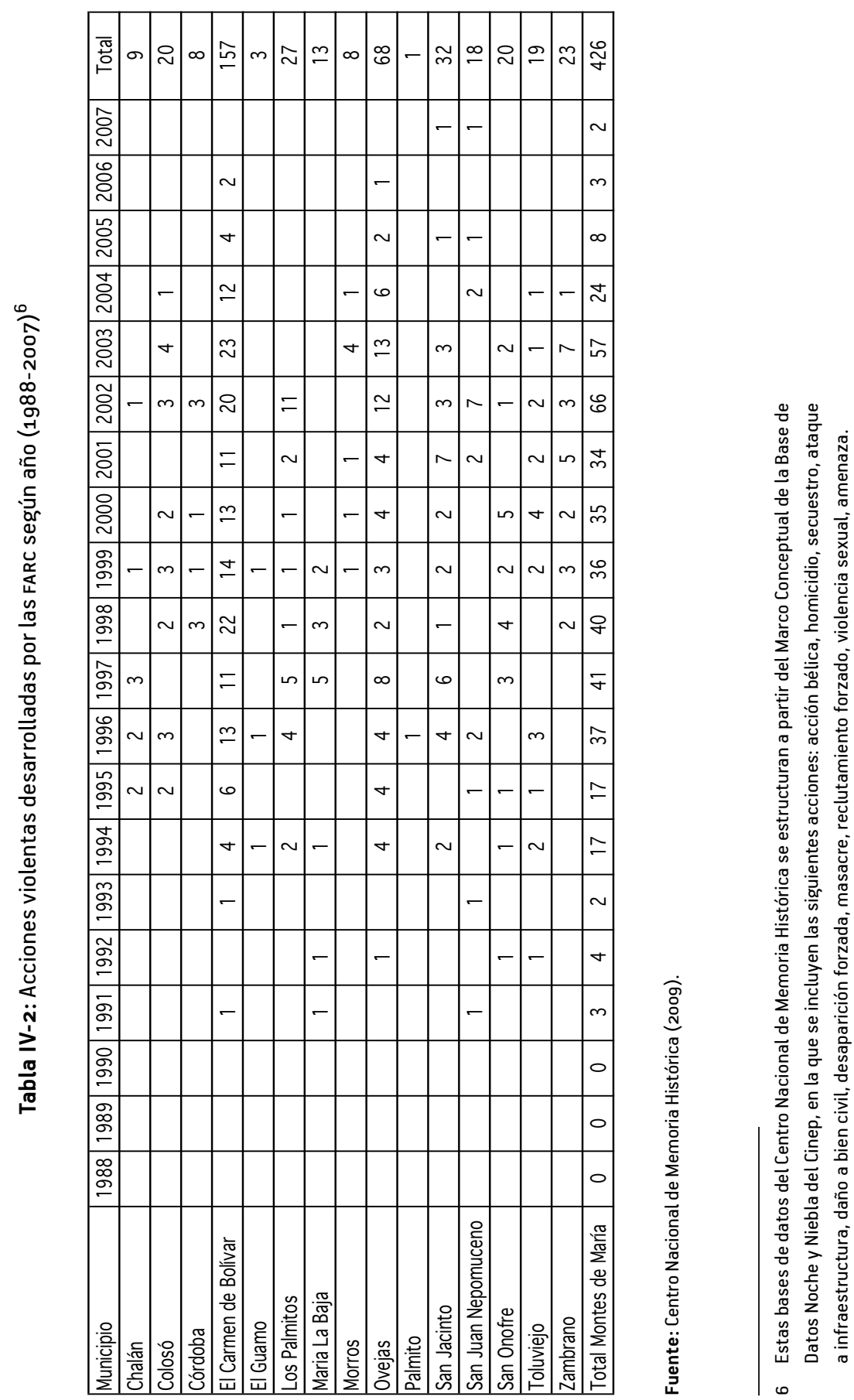
Los relatos recogidos en la región y los análisis sistematizados en distintos informes dan cuenta de una guerrilla que irregularizó todo su accionar, generando profundas brechas con la población civil; así mismo, una organización que no respetó las convenciones de la guerra:

Se trata de una guerrilla que concentró cerca de la mitad de su actividad en acciones bélicas con o sin derivación en infracciones al DIH, y la otra mitad con infracciones directas al DIH, y altos niveles de ocurrencia de ambas entre 1996 y 2004. Si se exploran unas y otras, se observa que en las primeras prevalecen los combates, seguidos de las emboscadas y las incursiones; mientras que en las segundas prevalecen los homicidios selectivos, los secuestros, el pillaje y la destrucción de bienes civiles. Se trata entonces de una guerrilla no sólo combativa sino depredadora. (CNMH, 2009: 186)

Esto desencadenó una reacción de grupos contrainsurgentes vinculados a las estructuras de las AUc, quienes a partir del año 1996 van a intensificar su presencia en la región, en los territorios de mayor presencia guerrillera; sin embargo, la estela de víctimas que dejaron a su paso no necesariamente está asociada a enfrentamientos directos contra estas organizaciones ilegales, por el contrario, se concentra en afectaciones directas contra la población civil. Así, diversas masacres, desplazamientos y acciones irregulares contra la población y contra la Fuerza Pública van a marcar la presencia de este grupo ilegal en el territorio.

A estas cifras se le deben sumar los datos sobre militares víctimas, de los cuales se reportan 263 casos: 141 asesinados y 122 heridos, según la Base de Datos de la Dirección de Víctimas y Memoria Histórica de la Armada Nacional. Estas cifras también pueden cualificarse al comprender la complejidad de los contextos en los que tuvieron que operar los miembros de dicha Fuerza Militar. Los relatos recabados por los Oficiales y Suboficiales de la Armada Nacional afectados por el conflicto armado documentan cómo los grupos armados ilegales - principalmente las FARC - crearon una tecnología artesanal, rudimentaria y asesina para atacar a la población civil y a soldados y policías. 


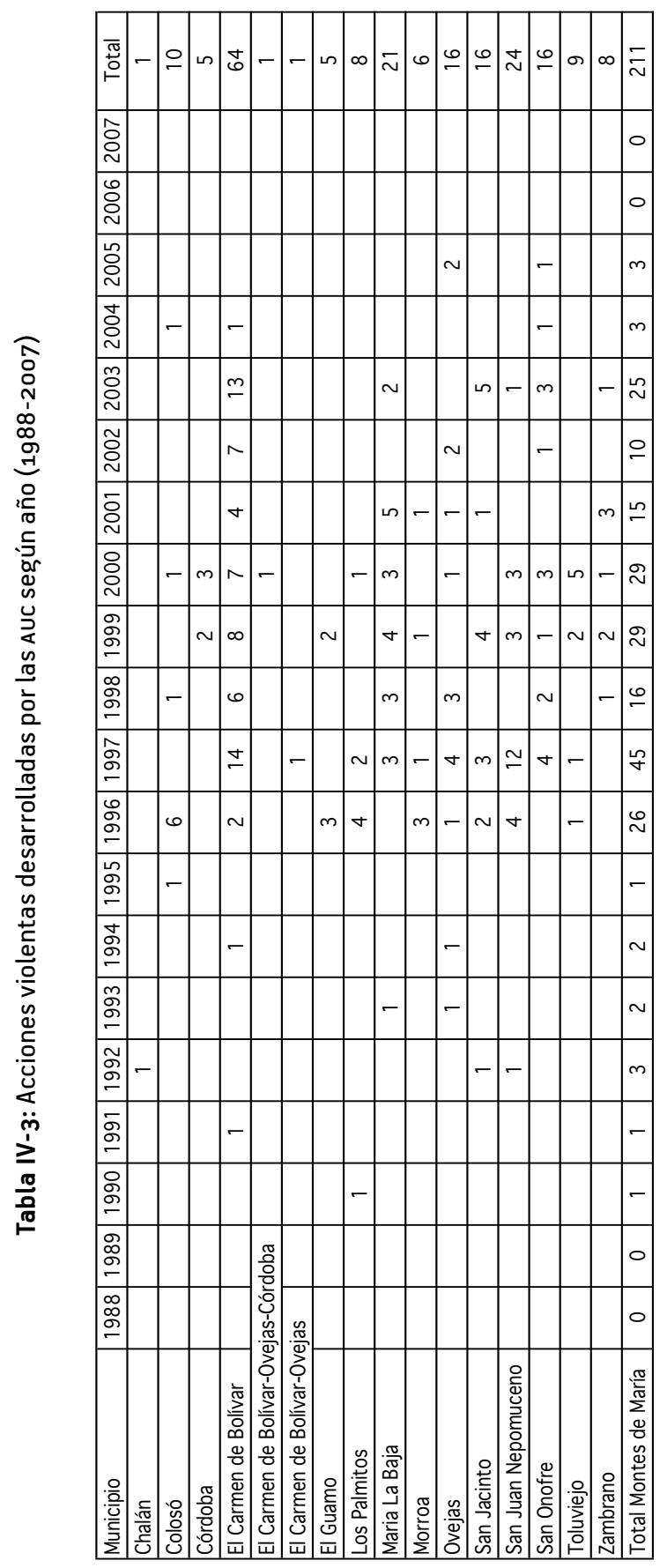

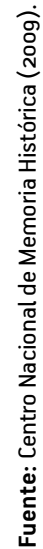


Todo empezó con lo que ellos llamaban el "sombrero chino", haga de cuenta como una mecha de tejo gigante que explotaba y mataba al que estuviera cerca; luego vinieron los "balones" o "bolas de fuego", que como su nombre lo indica era esferas cargadas de explosivo que ponían a correr en contra de nosotros y que eran muy difíciles de esquivar; después entraron en una estrategia de poner pequeñas minas para impedir que el Ejército entrara, ellos decían que para qué tanto explosivo si igual jodían a la tropa. Luego este "Martín Caballero” buscó como perfeccionar todo eso: hizo más rápidos los cilindros de gas, repleto todo de metralla, le metió estiércol y heces humanas a la metralla para generar infecciones, en fin. Ese tipo entendió que no tenía sentido pelear de frente, que haciéndonos volar era suficiente. (Castiblanco et al., 2017)

\section{Las memorias de la violencia}

Figura IV-3. El resistente

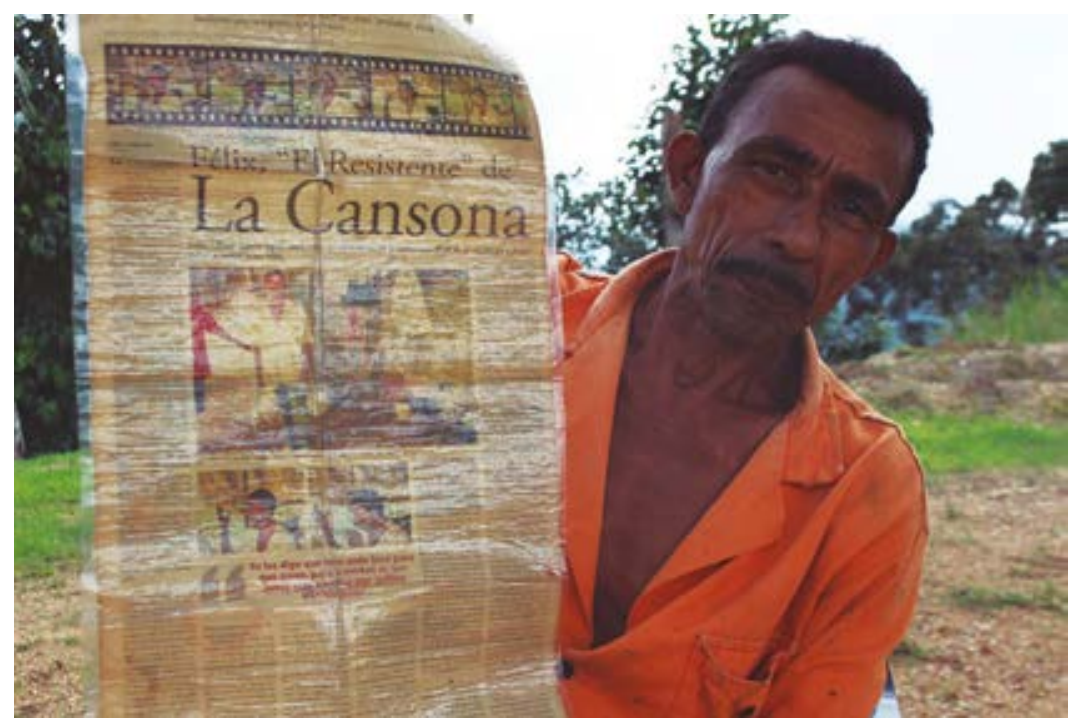

Fotografía de María del Mar Martínez, Cerro La Cansona, diciembre de 2017. 
Para dar cuenta de la realidad de un territorio tan complejo como los Montes de María y, más aún, comprender la guerra que ocupó a esta subregión durante los 10 años más violentos de Colombia contemporánea, es necesario ver más allá, desdibujar las cifras, humanizar los números y convertirlos en historias reales de quienes terminaron viviendo en medio de un conflicto que nunca eligieron, por habitar en "la despensa del caribe", vivir en un corredor estratégico, nacer en uno de los territorios más codiciados. Humanizar las dimensiones del conflicto en el marco de la reconstrucción de la memoria histórica en los territorios implica entender aquellos testimonios, versiones, anécdotas, desde las más pequeñas y aparentemente irrelevantes, hasta los hechos más impactantes, entendiendo que se trata en ambos casos de imágenes de la realidad subjetiva de los individuos, a partir de la cual se abre el camino para revivir las voces que fueron silenciadas en una región asediada por la violencia, el dolor y la zozobra.

La guerra no selleva solo la ilusión de lo que alguna vez produjo la tierra, las hectáreas trabajadas, los cuerpos enterrados; se lleva vidas enteras que durante años se construyeron, seres humanos que tenían sueños y cuya muerte implicó la ausencia de todo lo que ellos aportaban para el mundo. Cada pérdida queda escrita en los ojos de los que quedaron para contar la historia y en aquella lucha al emprender el reto de no olvidar, pero también el reto de seguir adelante a pesar del dolor.

Este ejercicio implica ir más allá de los hechos puntuales más dramáticos y más evidentes de la victimización, pues la complejidad de la guerra estructural que circundó el territorio de los Montes de María permeó absolutamente todas las esferas de la vida social y logró transformar la cotidianidad y la vida de todos los testigos de los hechos, por lo cual no es extraño escuchar entre sus habitantes, al hacer referencia al conflicto, que toda la región se convirtió en víctima del conflicto armado y todos, absolutamente todos, sufrieron sus consecuencias a diferentes niveles; transformó el folclor, la alegría, la confianza, convirtió a todos en potenciales sospechosos, silenció una tierra donde el ruido y la música eran por tradición la esencia para sentir la vida, donde todos eran compadres, donde no se cerraban las puertas de las casas. 
Esta sección se ha desarrollado sin la intención explícita de dar cuenta de una generalización del estado de las víctimas o de los habitantes de los Montes de María durante los años del conflicto, se ha realizado con el fin de reconocer diferentes dimensiones de la violencia desde el punto de vista de más de veinte testimonios, los testigos cuya vida fue surcada de alguna manera. En medio de este contexto se pretende identificar los puntos de encuentro y de diferencia entre testimonios, por lo tanto, más que brindar una verdad absoluta, esta sección busca dar voz a personas que vivieron la guerra desde diferentes perspectivas, culturales, territoriales y sociales.

Con lo anterior se pone de presente que, al tratarse de versiones de la historia, este apartado debe ser leído a la luz de los capítulos sobre dinámicas del conflicto, causas estructurales del conflicto y los casos judiciales dentro de los cuales se extiende la información de los casos mencionados en el presente apartado, capítulos que hacen un ejercicio de constatación de fuentes con suficiente rigurosidad. En este apartado, se ha abierto un compás de libertad para dimensionar la naturaleza misma de los relatos.

$\mathrm{Al}$ analizar los testimonios recopilados, se identifican cinco temas dentro de los cuales se puede desarrollar la complejidad de las vivencias representadas a través de estos; el primero refiere a la territorialización de la violencia en los siete casos específicos de poblaciones que se vieron afectadas por el conflicto. En un segundo momento, se desarrolla la temática de estigmatización de la población, la cual termina siendo una de las particularidades comunes de los diferentes territorios que vivieron el conflicto, una estrategia que alejó a las poblaciones y las convirtió en más vulnerables ante la violencia y el control.

A continuación, se analizan las consecuencias de la guerra, las preocupaciones actuales frente a las dinámicas sociales y comunitarias del territorio desde la visión de los pobladores, visibilizando, algunos de los efectos que viven los habitantes de los Montes de María y las personas que estuvieron involucradas en las hostilidades. Por último, se pone en relieve la recuperación del tejido social, relatando algunas de las estrategias que desde la perspectiva de la población civil incidieron para una transición hacia la soberanía de los pobladores sobre su territorio, en distintas etapas del conflicto. 


\section{Territorialización de la violencia}

Los años de conflicto dentro de la región de Montes de María, si bien tuvieron etapas y fraccionamientos temporales comunes, contaron igualmente con una división espacial fundamental, entendida desde las particularidades y diferencias geográficas, poblacionales, históricas entre los municipios, corregimientos o caseríos. La comprensión de las relaciones y dinámicas humanas con el espacio es primordial en una región cuyas particularidades físicas confluían con los intereses y nivel de influencia de un grupo u otro: Alta Montaña, dentro de la cual el asentamiento de grupos guerrilleros se hizo más evidente, Montaña Media, se encontraban cascos urbanos con mayor densidad demográfica y Montaña Baja, cerca al mar, en la cual la influencia y control de los grupos de autodefensas ilegales fueron mayores; cada una cuenta con características diferentes a nivel físico, económico, productivo y social. Es de entender dentro de las particularidades anunciadas anteriormente que el estado de las vías de acceso en la época dificultaba el rápido y permanente intercambio entre las diferentes poblaciones e incluso de las mismas poblaciones con las instituciones estatales, lo cual también se convirtió en un factor de alta incidencia para el desarrollo y expansión de las dinámicas del conflicto.

Así mismo, los grupos armados ilegales incidieron de formas muy variadas en las comunidades en los diferentes contextos, en algunas generaron complicidades, las empatías las tenían ganadas casi siempre por la fuerza, lo cual generó dinámicas de asentamiento o paternalismo, convirtiéndolos en blanco de otras organizaciones ilegales. En estos casos, el terrorismo se empleaba para atemorizar a la población, e intentar contrarrestar el poder que ejercían de forma arbitraria otros grupos ilegales que ya tenían controlada a la población. Es este el contexto de muchas de las masacres que se perpetraron en esta zona.

En este apartado se da cuenta de dicha complejidad a partir de las poblaciones del municipio de San Onofre en su cabecera municipal y en uno de sus corregimientos, Rincón del Mar, Chengue, corregimiento de Ovejas (Sucre), Chalán (Sucre) y La Cansona, El Salado, Macayepo, corregimientos de Carmen de Bolívar (Bolívar). Pretendemos, pues, hacer una descripción de las perspectivas de la memoria colectiva, desde algunos de sus pobladores, cómo ellos vivieron la guerra y cómo se transformaron sus vidas a partir de esta crisis en tierras diferentes. 


\section{San Onofre (Sucre)}

Antes de que el conflicto llegara a San Onofre era una vida feliz, tranquila, había un ambiente de paz, los comerciantes los ganaderos, los agricultores vivían tranquilos, la economía era próspera, no había escasez. Si bien hubo incidencia de grupos guerrilleros dentro de la región, su nivel de violencia no se podría estimar en gran escala a nivel social. No obstante, a pesar de que la crueldad y la intimidación contra los pobladores, estos factores no se desarrollaron en gran escala como en otros municipios de la región, y los niveles de mortalidad por el conflicto armado durante su presencia no fueron críticos; hubo extorsión, cobro de vacunas y secuestro a los ganaderos y a algunos comerciantes, con propósitos de financiación de los grupos ilegales.

Dentro del testimonio del habitante de San Onofre, Humberto Villaba, se evidenció que dicho fenómeno no parecía atormentar a gran escala a la mayoría de la población, pues sus dinámicas territoriales no se habían fortalecido a un nivel crítico.

Aquí hubo uno que murió en el monte, que lo secuestraron, pero fue porque los familiares dieron la plata pero como el señor sufría del corazón se murió por accidente en ese momento y cuando lo entregaron ya estaba muerto, no lo mataron, pero esos grupos aquí no hicieron matar prácticamente. (Humberto Villaba, San Onofre, 2017)

Sin embargo, la historia cambia cuando se habla de los grupos de autodefensas ilegales, pues esta es una zona donde el fortalecimiento desmedido de este tipo particular de organización ilegal tuvo mayor facilidad para su expansión y su posicionamiento y control por medio de la violencia e intimidación sobre la población civil en todos los niveles sociales y económicos, llevándolo incluso a un nivel de convivencia permanente mientras se incrementaban los niveles de violencia y criminalidad de manera exponencial en la zona.

Eso no fue paramilitarismo, fueron bandidos, porque los paramilitares, valga la redundancia, son los que trabajan para los militares, pero aquí ellos nunca trabajaron para los militares, trabajaban para ellos mismos, mataron gente 
para coger el poder, atacaron primeramente a los rateritos de clase baja, y después terminaron matando a los políticos. (Humberto Villalba, 2017)

Es importante decir que San Onofre, desafortunadamente, fue el epicentro de acción de Rodrigo Mercado Peluffo, alias 'Cadena', uno de los cabecillas del Bloque Héroes de Montes de María, "El pasaba por aquí como Pedro por su casa, él jugaba gallos en la gallera [...] como él era el manda más" (Humberto Villalba, 2017). Por lo tanto, podríamos decir que esta fue una de las regiones donde hubo mayor impacto del control del Bloque Héroes de los Montes de María. En el Palmar, una finca vía a Berrugas (Sucre), establecieron su campamento y desde ahí desarrollaron gran cantidad de los asesinatos, castigos y suplicios contra los habitantes de todo el municipio, y ahí mismo, según la versión de los pobladores, se enterraban los cuerpos de las víctimas de esta organización ilegal, sin embargo, para los pobladores, aunque se han desarrollado investigaciones alrededor de este emblemático lugar, sigue existiendo una verdad que no ha quedado al descubierto completamente y que debe ser contada.

Aquí se desconocen muchas cosas, por ejemplo ¿qué pasó en el Palmar?, el año pasado tuvimos la oportunidad de plasmar en una pintura todo lo que pasó en el municipio [...] ahí plasmamos toda la violencia que sufrió los corregimientos, los caseríos y todo el municipio de San Onofre, [...] en ese palo de caucho hubo mucho asesinatos, violaciones, ahí había una laguna con cocodrilos donde llevaban a los jóvenes, a las mujeres que no se portaban bien les cortaban el cabello, les rapaban la cabeza y las violaban, aunque tuvieran hijos allá se aguantaban tantos días con ellos, y el día que a los paramilitares de les daba la gana regresaban a sus casas [...] (Norlis Judith, San Onofre, 2017)

Poco a poco, se fue desdibujando más y más el control del Estado sobre las tierras de este territorio y paulatinamente las instituciones públicas, políticas y sociales se vieron vinculadas y subyugadas ante las dinámicas de este grupo armado ilegal, repercutiendo en lo que periodísticamente se denominó la "parapolítica”. Según la versión de los testimoniantes, la pérdida de confianza en la Fuerza Pública y en 
el rendimiento de otras instituciones estatales marcó un momento histórico de este municipio.

Las dinámicas de control de la población en este municipio, según las narrativas estudiadas, variaron entre la extorsión, el despojo de tierras y el desplazamiento forzado y tortura, así como gran cantidad de asesinatos selectivos. Al llegar a los estamentos gubernamentales y políticos tomaron en sus manos mecanismos asociados al clientelismo armado.
A la cuñada mía le hicieron un montaje para desplazarla porque ella era fiscal en esa época, le ofrecían la plata que fuera y ella nunca les recibió cinco centavos. Le formaron un complot para desplazarla y cumplieron su objetivo [...]. (Humberto Villalba, San Onofre, 2017)

Las doctrinas de este grupo ilegal, el posicionamiento de nuevas reglas a través del miedo y la violencia, desarrollaron estadios de silencio dentro de las comunidades. Para detallar de manera más profunda la trasformación de la cotidianidad a partir del conflicto armado que alcanzó a vivir la población del municipio de San Onofre, podríamos remitirnos como un ejemplo a la población de Rincón del Mar, la cual al igual que muchas otras poblaciones tuvo que vivir el asentamiento de las autodefensas ilegales dentro de su territorio.

Una vez mataron a dos jóvenes que eran hermanos, eran las 6:30 de la tarde, fue algo que nos consternó porque nunca en nuestro pueblo habíamos visto eso, fue algo que nos marcó, ellos lo hicieron para mostrar el dominio que querían tener en nuestra comunidad, y lo lograron, nos atemorizaron, y desde ahí empezó una vida donde ellos se veían como legalizados en nuestro medio, aquí el mínimo problema se les llevaba a ellos porque los veíamos como si fueran la ley y la justicia porque ellos compartían con la policía nacional, con el ejército, entonces nosotros nos dábamos cuenta de que si nosotros nos poníamos en contra, ¿qué iba a pasar? Porque nosotros veíamos a los alcaldes, los senadores, los gobernadores, todos eran una sola intervención con ellos, entonces ¿qué nos tocaba a nosotros? Quedarnos callados y sumergidos a lo que ellos hacían. (Oniris Díaz, Rincón del mar, 2017) 
La anterior frase podría llegar a resumir las intimidaciones, coacciones y violaciones de derechos que el corregimiento de Rincón del Mar enfrentó durante los momentos de conflicto. Este hermoso corregimiento cuyas playas paradisiacas lo convirtieron en un atractivo turístico para los pobladores de San Onofre y Sincelejo, fue elegido como lugar dormitorio del grupo armado ilegal, a diferencia de otras poblaciones donde controlaban a través de visitas itinerantes, colaboradores e informantes.

\begin{abstract}
Nos vimos abruptamente interrumpidos en nuestra vida normal en 1997 cuando unos grupos al margen de la ley que estaban aquí cerca en nuestra población empezaron a hacer incidencia en toda nuestra vida cotidiana, primero vino un grupo que estaba aquí en Plan Parejo, pero ellos solo venían lo fines de semana porque les gustaba mucho el pueblo, donde ellos estaban lo bombardearon, se dice que eran las AUC, cuando los bombardean a ellos aparece un nuevo grupo AUC al mando de Rodrigo Mercado Peluffo alias Cadena, ese señor si se mantenía acá, al punto de que tuvieron casa aquí en Rincón del Mar, se establecieron en la población. [...]
\end{abstract}

Entonces ellos iban a nuestras casas nos sacaban para hacer reuniones [...] donde nos decían todo lo que debíamos hacer, a qué hora debíamos acostarnos, levantarnos, que debíamos hacer con nuestros hijos, ellos influenciaron en toda nuestra vida. [...]

Aquí nadie podía estar después de las 6 de la tarde en la calle e incluso os decíamos el candidato político por el que debíamos votar. (Oniris Díaz, Rincón del Mar, 2017)

Los repertorios de castigo y suplicio conseguían aterrorizar a la población de San Onofre en general, exponiéndolos a una década de silencio, desde 1996 hasta 2004. "Aquí las mujeres cuando tenían una dificultad la una con la otra las ponían a barrer todo el pueblo para castigarlas, violaban a las mujeres, aquí hubo una joven que por no dejarse... le cortaron el cuero cabelludo" (Oniris Díaz, 2017). Dentro de este contexto, la violencia de género no se hizo esperar, en San Onofre existieron, según las versiones de las víctimas, muchos casos de violaciones y maltratos a los derechos de las mujeres por medio de 
la vulneración sexual y la esclavitud doméstica, que aún hoy no se han denunciado en su mayoría, pues eran dinámicas sistemáticas normalizadas en medio de las cuales el silencio y la vergüenza visibilizaban el fenómeno como tal7.

La vulneración de derecho de mujeres se dio en todo no solo en violencia sexual, la violencia sexual se le cogían más que todo para castigar a los hombres, es decir, fulano de tal es el marido de fulana de tal pero la mujer de él esta buena. Ellos decían "es que las negras..." y yo se lo recalcaba mucho a la asesora, que a nosotras nos pasó esto por ser afro, por ser negras, porque es que los paramilitares decían que las negras eran muy sabrosas, aunque vivieran con una abogada, con una profesora con una persona de la alta sociedad, con una persona blanca ellos a las negras las veían como objeto sexual, para castigar a los hombres, para dárselas de que se habían acostado con la mujer de fulano de tal, y las niñas también. (Norlis Judith Herrera, 2017)

Los testimonios analizados evidencian una apatía generalizada ante las dinámicas de los grupos, pues sus repertorios de violencia generaron relaciones de opresión. Los cambios dentro de las relaciones sociales se dieron como una consecuencia evidente, el desarrollo de la criminalidad y el ejemplo de violencia ante las juventudes generaron una sociedad que aún se encuentra en el camino para desdibujar ese legado.

\section{La Cansona (Bolívar)}

En los Montes de María existen tres cerros ubicados a 800 metros sobre el nivel del mar, desde los cuales se puede apreciar, una vista de casi 360 grados de montes, canales y espejos de agua, corregimientos, cabeceras municipales, ciénagas y todo el terreno montañoso de la zona, el caserío de La Cansona es uno de ellos, y consecuentemente,

7 El fenómeno de la violencia sexual en este territorio ha sido analizado previamente en el capítulo 2, en el que se estudian las dinámicas del conflicto. 
fue uno de los territorios más asediados por el conflicto y los enfrentamientos armados dentro del Carmen de Bolívar. Alguna vez las montañas de la Cansona estuvieron constituidas por fincas de gran extensión, que pertenecían a hacendados y personas adineradas que con sus cultivos de café y más tarde las plantaciones de aguacate, un producto bastante rentable que disparó la economía de los dueños de las tierras, lograban ocupar a cientos de campesinos. Se decía que eran las fincas más prósperas de Carmen de Bolívar.

Sus características hicieron que grupos guerrilleros lo reconocieran como un sector estratégico de alta presencia e incidencia, además, este caserío quedaba en un corredor hacia Macayepo y más adelante a San Onofre, el control sobre la zona y el posicionamiento de campamentos itinerantes de la guerrilla en este tramo lo consolidó como una zona de alto impacto en la cual los grupos armados ilegales extorsionaban y secuestraban a los dueños de las grandes fincas productoras, que para entonces en su mayoría hacían parte de la clase alta de Carmen de Bolívar, con el fin de financiar la organización. Estas dinámicas se fueron recrudeciendo y como consecuencia poco a poco los terratenientes fueron abandonando sus fincas y dejándolas en manos de sus trabajadores.

Esta finca tiene 72 hectáreas, en época de aguacate había mínimo 20 personas trabajando [...] pero no todos los días, dos o tres días a la semana [...] cuando era café era mucha más porque el café necesita mucha obra de mano. Nosotros éramos siete hermanos, de los 7 somos tres varones, mi hermano mayor estaba estudiando en México, allá duró estudiando medicina, el otro estaba estudiando arquitectura, yo terminé bachillerato, a raíz de eso yo era el compañero de mi padre en la finca, nos veníamos martes, regresábamos viernes aquí, a la muerte de mi padre quedé yo en la finca, a raíz de eso, de que ellos sabían que yo tenía esta finca fue que me buscaron. Es más, me secuestraron un sobrino [...]. (Héctor Romero, La Cansona, 2017)

Al quedarse las tierras sin sus dueños oficiales, los campesinos cuidaron las fincas y fueron ellos quienes a partir de 1997 empezaron a presenciar los constantes enfrentamientos dentro de la zona de la Cansona entre guerrilla, autodefensas ilegales y Fuerzas Militares 
lo cual generó desplazamientos a gran escala dejando abandonada la mayoría de tierras, fincas y viviendas, convirtiéndolas en un campo de guerra permanente.

El desplazamiento, el último que tuvimos, fue el once de julio de 2000 que fue cuando llegaron fuerzas especiales a combatir la guerrilla en zona alta de la región. Esa vez, ya como nosotros estábamos acostumbrados a esos combates y enfrentamientos entre guerrilla, paramilitares y ejército, entonces se nos hacía común que eso pasara, es un momento a otro mi mama dijo, nos tenemos que ir, lo que pasa es que esta vez fue distinto, esta vez hubo muchos más muertos. En ese momento era yo el mayor de la casa, tenía 14 años, me toco sacar a mi hermano, sacarlo, empezar de ceros, dejar todo tirado aquí, las cosechas. (Frank Enrique Tapia, Carmen de Bolívar, 2017)

Los campesinos que residían y resistían permaneciendo en zonas apartadas de los cascos urbanos o en corredores estratégicos tenían que estar en contacto permanente con diferentes actores, los cuales les pedían cocinar en sus casas o, en el mejor de los casos, pedían agua y leña para poder continuar con su camino.

Era imposible negarse, pero las consecuencias eran dramáticas, pues al brindarle agua a un grupo, los campesinos se convertían en blanco del otro. En esa dinámica cuarenta familias del corregimiento de La Cansona fueron desplazadas, pues los riesgos de vivir en el campo eran cada vez más cercanos.

Aquí vinieron dos guerrilleros cuando hicieron la masacre unos paracos aquí en El Ojito, vinieron dos guerrilleros, y me encontraron en la puerta con la rula, y me encontraron, y uno sacó la antena de radio, yo dije "me vinieron a matar". [...] hacia seis meses que la bajada de allí habían hecho una reunión en la que habían dicho que si había plomo, el que se fuera no podía volver y a mí se me grabó eso. Entonces yo me quedé y no me fui cuando la masacre, cuando me preguntó, yo le respondí que yo había grabado sus propias palabras en mi cabeza. Que si quería que me fuera me diera dos horas para sacar todo, pero él se dio la vuelta y dijo, si no te fuiste 
ya, ya que te vas a ir. Y se fue. Yo agradecí a Dios porque él me había cuidado de que no me hicieran nada. (Félix 'el Resistente', La Cansona, 2017)

La lucha constante de la Armada Nacional por recuperar La Cansona rindió frutos en 2008, cuando se declaró por fin zona libre de guerrilla y de las AUc. Poco a poco al lugar fue retornando la belleza y tranquilidad, además del posicionamiento de un puesto de la Infantería de Marina en la punta del Cerro, hechos que hicieron que se convirtiera en un atractivo turístico cuya vigencia llega a la actualidad y donde se están emprendiendo nuevos proyectos de cultivo para la recuperación de la economía territorial.

\section{El Salado (Bolívar)}

La comunidad fue cogiendo miedo, siempre se hablaba de que nos iban a mandar a desocupar que el territorio se lo iban a tomar los paras. (Jaquelin Cohen, El Salado, 2017)

Este era un corregimiento muy próspero, limpio, con unas costumbres sanas, sin delincuencia o grupos al margen de la ley. La infraestructura de este corregimiento, según el testimonio de Jaqueline, habitante desde niña, era mejor, incluso mucho más adecuada que en la actualidad, a pesar de la inversión tan alta que, dice ella, se ha hecho dentro del pueblo.

Por otro lado, las costumbres tradicionales eran los pilares del pueblo, las mujeres representaban el cuidado del hogar y el servicio en la comunidad.

Las mujeres eran acompañadas por su maridos al trabajo, [...] a criar sus hijos tenían su hogar un hogar lindo no se veía tanta violencia, los hombres si eran un poco más machistas porque los que trabajaban y los del mando en la casa eran los hombres eran los cabeza de hogar pero eran más respetadas las cosas no se veían cosas de violación ni nada por el estilo, esto era un pueblo muy prospero aquí la mayoría tenía, el que menos tenía, tenía una vaca y de eso vivía, aunque las 
tierras no fueran de ellos pero tenían donde tenerla trabajaban las tierras que eran de otras personas pero tenían su vaquita ahí y el que era propietario de la tierra no le decía usted no puede tener esa vaca. (Jaqueline Cohen, El Salado, 2017)

En este territorio se había edificado una cárcel, lugar desde donde se posicionaba la Fuerza Pública en el corregimiento, sin embargo, esta cárcel se derribó al no haber lugar para la Policía Nacional, lo cual llevó a que esta tuviera que salir del corregimiento. La percepción de seguridad se mantuvo durante algunos años, sin embargo, la dificultad de acceso a estos lugares se convierte en un caldo de cultivo para el asedio y posicionamiento de grupos armados ilegales. Fueron las organizaciones guerrilleras quienes primero tomaron ventaja de esta situación, iniciando procesos de reclutamiento forzado.

La relación prácticamente no fue toda la comunidad fueron unos pocos los que tuvieron una relación cuando ya fue entrando los grupos al margen de la ley que ellos lo que hacían era como que buscar gente para ingresar a las filas enamorando gente.

Ellos lo que hacían era como invitarlos y así se iban quedando y bueno algunos se quedaron pero hubo mucha gente que no estaban de acuerdo pero por el miedo que se tenía no se hacía nada no se hablaba, no se informaba, todo mundo callaba, entonces yo creo que eso también fue lo que llevó a esta comunidad a que nos hicieran lo que nos hicieron después de un tiempo [...] Esa gente no vivía aquí en el Salado como decían, pasaban por aquí por el Salado pero no vivían. $\mathrm{O}$ sea, esto es un corregimiento que tiene varias salidas, tiene la salida a Canutalito, la salida a San Andrés y la salida hacia abajo a Zambrano; eran caminos de herradura pero que si podían transitar vehículos aunque era muy pesado cuando llovía pero se transitaba entonces por eso era que ellos buscaban al conectarse un lado con el otro y ahí ya fue como la comunidad fue cogiendo miedo siempre se hablaba de que nos iban a mandar a desocupar que el territorio se lo iba a tomar los paras. (Jaqueline Cohen, el Salado, 2017) 
A partir de este momento, la comunidad fue poco a poco consumida por el miedo, pues los grupos estaban alertando permanentemente sobre los posibles enfrentamientos y acosos que la población estaba en potencia de tener. Infortunadamente, en el año 1997 se hicieron realidad estos presagios, la población sufrió por primera vez el dolor del conflicto en carne propia, esto fue lo que se conocería como la primera masacre que hubo en El Salado.

La primera vez se metieron en el 97 un grupo ellos mismos se identificaron como la AUc cogieron unas personas las llevaron hasta el parque 5 de noviembre que queda en el barrio abajo, y ahí mataron cuatro personas y se llevaron un señor y lo desaparecieron que nunca se ha sabido donde lo dejaron eso tampoco se denunció, el pueblo se desplazó aunque en esa época nada más demoramos tres meses desplazados, ni el gobierno ni nadie tomó cartas en el asunto. (Jaqueline Cohen, El Salado, 2017)

El asentamiento urbano de El Salado quedó por primera vez en su historia abandonado, la población se dirigió a los municipios aledaños, muchos de ellos buscaron refugio en poblaciones más grandes en las que, por lo menos, existiera la presencia de instituciones estatales. Sin embargo, la situación económica, las condiciones de pauperización que debían enfrentar en las poblaciones urbanas, el amor y arraigo a sus tierras los llevaron a retornar al poco tiempo;

regresamos ya otra vez, cogimos la rutina del trabajo que teníamos de volver a empezar de nuevo porque en ese instante el que tenía sus cosas no las mal vendió como en el segundo porque en el primero si logramos traer cosas de las que nos llevamos. (Jaqueline Cohen, El Salado, 2017)

Aunque con mucho esfuerzo, poco a poco las personas lograron volver a la cotidianidad, esta vez más temerosas pues habían conocido la gravedad del conflicto. Sin embargo, cuando hasta ahora se recuperaban del primer impacto, tan solo tres años después el 17 de febrero del año 2000, sucedió uno de los hechos más enigmáticos y crudos de la guerra en la región, la masacre de El Salado, en la cual al ritmo 
de la gaita, tambores y trago, durante tres días completos miembros de las autodefensas ilegales se tomaron la cancha de El Salado, un lugar que antes había sido sede de festivales, juegos, risas e infancia, el cual se convirtió en un espacio para asesinar de las maneras más crueles a los miembros de una población que se había estigmatizado como guerrillera.

¿Quién pagó? ¿Por qué lo hicieron? De pronto ellos querían una guerra con la guerrilla, pero que nosotros no éramos los guerrilleros, ellos tenían que buscarlos no aquí en el pueblo como decían que ellos vivían aquí, que nosotros nos uniformábamos en la noche y en el día éramos campesinos, eso es una vil mentira si hubiese sido así yo me hubiera atrevido confesarlo porque yo digo ante Dios y aquí en la tierra no hay nada oculto todo sale algún día pero sale entonces yo si quisiera que eso se esclareciera o sea que hubiera una verdad.

O sea no sé la intencionalidad con que la hicieron, nunca he alcanzado a saber ni imaginarme yo de pronto digo estas tierras por acá de pronto son unas tierras fértiles, contamos con un ojo de agua que de pronto en otras regiones no las hay, pero si es así de pronto en otras comunidades también hay lo mismo entonces no le veo, no sé, no entiendo el por qué todavía. (Jaqueline Cohen, El Salado, 2017)

Era una población pequeña, todos se conocían entre sí, así que cada muerte significó una gran pérdida, no fue el hecho del asesinato lo único que logró impactar y aterrorizar a los pobladores de El Salado, la cancha se convirtió en un escenario de teatralización de la violencia donde murieron muchas personas inocentes que nada tenían que ver con esa guerra. No fueron cuerpos solamente, fueron vidas enteras, personas que alguna vez habían saludado, compañeros con los que alguna vez habían trabajado de la mano, campesinos con quienes alguna vez habían intercambiado algún producto.

El señor Enriquito era una persona gallera que no se metía con nadie. Le gustaba era el fútbol, le gustaba era enrazar las burras con caballos y sacaba mulos, era dedicado a su finca, 
o sea, era un señor que no se metía con absolutamente nadie, vivía su vida con su señora y sus hijos y por tener una carne guardada en un enfriador de un sobrino al que se le había caído una vaca [...] la encuentran entonces la pelaron y guardaron la carne ahí, ya lo mataron porque la carne era de la guerrilla.

El señor Emiro fue otro señor trabajador, campesino, vivía prácticamente era en el monte, vivía de lo que producía, le gustaba mucho el fútbol, o sea él discutía de pronto las cosas de fútbol era muy fanático a eso y también lo mataron por quererlo matar, porque no tenía ninguna condición de que estuviera ni con un bando ni con el otro.

Mis primos salieron a recoger unos caballos a un monte, se encontraron con un grupo les preguntaron que cómo se llamaban, uno se llamaba Édgar Cohen y Ornedis Cohen, y por tener los apellidos Cohen dicen que por eso fue que los mataron, no sé en qué condiciones o en qué aspecto tendrían el apellido.

La muchacha que mataron era una muchacha de su familia, de su casa, era el primer hijo que iba a tener, vivía con un muchacho también joven como de dieciocho años, entonces decían que era mujer de un guerrillero, pero aquí nadie nunca supo si era o no mujer del guerrillero en realidad. $Y$ así la mayoría las mataron sin ninguna certeza de que fueran o no fueran. (Jaqueline Cohen, El Salado, 2017)

Tres días y dos noches, miembros del Bloque Héroes de Montes de María, se tomaron un corregimiento que en aquella época quedaba aproximadamente, según Jaqueline, entre dos y tres horas de la población de Carmen de Bolívar en condiciones climáticas y de seguridad óptimas, y cinco o más horas cuando era invierno y la vía se convertía en un lodazal con surcos que no permitían el acceso de ningún tipo de vehículo. Sin embargo, aunque las condiciones meteorológicas eran buenas, la falta de comunicaciones que contaba como limitante para la Fuerza Pública y las condiciones de seguridad de la zona implicaron un nivel de respuesta tardío para socorrer a los habitantes en medio de la masacre. Resulta entonces, para la mayoría de la población, 
impensable darle una explicación a la ausencia de socorro por parte de cualquier autoridad.

\begin{abstract}
Nada, no entró nadie, o sea no nos socorrió nadie. Y como en ese entonces el alcalde del Carmen era un apellido Cohen se dice que él sabía lo que estaba pasando y que no quiso que vinieran a ver qué era lo que estaba pasando acá en el pueblo, no le quiso dar la orden al ejército que hubiera a ver qué estaba pasando. (Jaqueline Cohen, El Salado, 2017)
\end{abstract}

Después de 72 horas de terror, por fin se fueron los miembros de las Auc del pueblo, y tras ellos un gran grupo de personas que habitaban este corregimiento en ese entonces, con el terror en sus ojos y las pocas pertenencias que pudieron recoger, vivieron en carne propia el flagelo del desplazamiento forzado, se dirigieron a poblaciones grandes, buscaron refugio, pero la hostilidad de las ciudades y la pobreza los hizo anhelar cada día los viejos tiempos en su casa, aquellos tiempos en los que no hacía falta tener monedas en la mano para poder comer, pues la tierra les daba lo que necesitaban. Fue quizá esto lo que los hizo, dos años después, un 18 de febrero, retornar a su pueblo por sus propios medios.

No alcanzaba para pagar el arriendo y comida y pagar los servicios, era duro, ya se fueron como poniendo de acuerdo las personas que querían retornar y en el 2002 en el mes de marzo, en el mes de febrero empezaron a reunirse, armaron un comité que se llama "Asodebol”, una asociación de desplazados de El Salado, se legalizaron y en la legalización que hicieron y eso ellos fueron recolectando como fondos con personas que quería aportar para regresar a El Salado.

En la primera entrada entró un carro lleno con unos treinta o cuarenta personas y no podían entrar estaba ya, la maleza se había cogido el Salado ya, entonces tuvieron que trochar desde la entrada hasta la iglesia y de ahí ya enseguida cogieron. Cuando ya se reunieron en la iglesia y eso, entonces ya fueron como haciendo trochas para cada quien ir mirando dónde quedaban las casas que habían dejado acá, entonces ya decidieron ahí sí, sin ningún acompañamiento 
ni de policía ni de ejército, o sea el Gobierno no les prestó un servicio en ese momento, y bueno ahí fueron haciendo y haciendo hasta que fueron limpiando por partes hasta que ya fueron retornando.

El primer retorno creo que fueron como de sesenta familias; se venían primero los hombres solos, hubo seis mujeres que eran las que venían y cocinaban, ya después sí se fueron viniendo. ¡Ay! Tenían muchachitos pequeños, entonces no había como seguridad de medicina, de un médico, de una buena alimentación, ah porque ellos prácticamente se alimentaban con lo que encontraron acá, lo que era la yuca, el ñame, la vitualla dice uno por acá, pero ellos tenían que salir a buscar con que se la iban a comer. (Jaqueline Cohen, El Salado, 2017)

Poco a poco, el pueblo que alguna vez había tenido que salir sin mirar atrás quiso salir adelante, en un principio con sus propias manos, y con unas condiciones de asedio por parte de las guerrillas, quienes querían retomar el control del territorio, en esta ocasión con menos éxito pues la población, ahora organizada, rechazó y a medida que fue pasando el tiempo y conforme se visibilizaba su situación hubo más manos que se unieron a este proyecto de resiliencia.

Las condiciones de seguridad han cambiado, la presencia de la Armada Nacional transformó la sensación de zozobra; la Acción Integral realizada ha permitido construir vasos comunicantes con esta Institución, superando las tensiones del pasado; sin embargo, aún hace falta la presencia de otras entidades del Estado, que acompañen el resurgir de El Salado.

\section{Macayepo, Carmen de Bolívar (Bolívar)}

En las espesuras de la alta montaña del municipio de Carmen de Bolívar, se encuentra ubicado el corregimiento de Macayepo, del cual hacen parte Limón, Joján, Jojancito, La Sierra, El Cielo, El Orejero, Venado, Verruga, Centro Alegre, Berruguita y El Aguacate, veredas y caseríos fundamentalmente dedicados a la producción y explotación de la tierra. Este corregimiento que alguna vez vivió tranquilo, al igual que todos los rincones de los Montes de María, sufrió la 
violencia de una manera dramática, al encontrarse acorralados por todos los grupos armados ilegales del conflicto cada uno con unas dinámicas y repertorios de violencia que determinaron la historia de este corregimiento.

Según Jhonny Alfredo Ramos, habitante de Macayepoy actual líder comunitario del corregimiento, el desarrollo del conflicto inició con las organizaciones campesinas inconformes con las condiciones de trabajo a las que se veían enfrentadas. Ahí, las guerrillas encontraron una excusa perfecta para proyectar el control de la zona y la población civil. Así pues, con el apoyo de organizaciones guerrilleras, desalojaron a la fuerza a los latifundistas, quienes vendieron sus tierras al Incora, quien posteriormente les hacía entrega a los usuarios, y ahí poco a poco los territorios fueron quedando en manos de los campesinos y las tierras de Macayepo se quedaron sin hacendados.

Los hacendados lo que hacían era enfrentarlos y sacarlos a la fuerza, incluso hubo muertos por eso. Por aquí estaba un señor Emberto Valle, que era un líder de campesinos, a él lo mataron, otro que vivía aquí, Juan García, y otro señor de más abajo, los sacaron una noche y los mataron a todos [...] todas esas muerte se las echaban a los dueños de tierras. (Jhonny Alfredo Ramos, Macayepo, 2017)

Según la versión de la población, a partir de esto los grupos de las AUC fueron ganando territorio en este corregimiento, y con esto se dio el primer gran paso a la agudización de la violencia y los conflictos dentro de los cuales la población, dados los asedios, intimidaciones y miedos, se vio expuesta y atenida a la voluntad de este actor emergente.

Según este testimonio, en esta población los que se encontraban en la zona rural alrededor del corregimiento eran tildados por los grupos de autodefensa como guerrilleros; por otro lado, las personas que hacían parte del casco urbano eran tildadas como "paramilitares", pues muchas de ellos configuraban una red de información, en la mayoría de los casos, de manera obligada.

Esta dinámica trasgredió las fronteras del corregimiento, existieron rivalidades entre las mismas poblaciones civiles a causa de esta polarización forzada de los pueblos. Para hablar de un caso específico, 
podríamos mentar la relación de enemistad que existía entre Macayepo y El Chengue, en medio de lo cual se dio uno de los eventos más trágicos de este corregimiento del municipio de Ovejas, la masacre.

Resulta que se da esa masacre porque allá se decía que era la casa de la guerrilla, los grupos de derecha decían eso, que en el Chengue eran guerrilleros, hasta que incursionaron y entraron y mataron, eso fue a raíz de unas tres muertes selectivas que hubo aquí en el corregimiento del Macayepo, y como forma de venganza. (Jhonny Alfredo Ramos, Macayepo, (2017)

Este estado de intranquilidad, inestabilidad y asedio, la población civil vivía cada vez más controlada por los grupos armados ilegales. Y así como en el Chengue, la detonación de esa bomba de tiempo, los convirtió en portadores de la misma historia pero con diferentes personajes.

La masacre de Macayepo, fue donde se desplazó todo el mundo, cuando eso pasa queda el pueblo fantasma, solo queda un señor [...] sacaron varias personas, incursionaron en toda la zona de la montaña, todo lo que iban encontrando a su paso lo arrasaban, mataron a cuatro señores, al regresar se llevaban todos [...] eso fueron los paramilitares. (Jhonny Alfredo Ramos, Macayepo, 2017)

Las guerrillas se apoderaron de las tierras que dejaron los campesinos e incluso llegaron a comercializar con los productos de estas tierras. Los campesinos iban al mercado y ahí reconocían los productos de sus propias fincas, lo cual aunado a la pobreza y el abandono que todos los campesinos pasaban al llegar a las ciudades y municipios que los recibieron, los incitó a repoblar la población. Propusieron entonces organizarse, pidiendo ayuda a la Fuerza Pública, específicamente a la Armada Nacional, con el fin de poco a poco repoblar y recuperar el territorio que alguna vez la guerra les había arrebatado; el acompañamiento de los infantes de Marina fue fundamental para el retorno.

Esta idea se planteó con el ánimo, no de repoblar en un principio sino de hacer provisión, recogían sus productos durante unas semanas y retornaban a las ciudades donde se habían refugiado. Se 
llevó a cabo en el marco del plan de recuperación de los Montes de María enmarcado en las políticas del Gobierno de la época. A través de la Armada Nacional, se dieron procesos de consolidación de la seguridad, y acciones de acompañamiento a la población civil.

Éramos objeto militar porque nos ayudaba la fuerza pública, la guerrilla en ese entonces nos hizo varias emboscadas durante este proceso. [...] tomamos a Macayepo como campamento, éramos un grupo de 40 vecinos, nos trajeron en helicóptero acompañados por la fuerza pública a tomar el pueblo para hacer el retorno después de haber tenido ya todo esto ganado, llegamos el 9 de septiembre del 2000 y limpiamos todo este pueblo y sus alrededores. (Jhonny Alfredo Ramos, Macayepo (2017)

Poco a poco, la población fue encontrando la oportunidad para retornar y volver a asentarse, fue un proceso largo y difícil pero finalmente con los años lograron recuperar sus tierras, sus cultivos, sus casas, su hogar.

Para el 21 de diciembre del 2004 se hizo el retorno, retornaron 20 familias fuera de los que estábamos acá que habíamos venido a preparar el territorio para los que venían, eso fue muy emocionante muy grande, la gente lloraba, no sé si de emoción o de tristeza, a algunos les daba felicidad regresar a los territorios y a otros les daba nostalgia recordar el lugar donde habían perdido a sus seres queridos (Jhonny Alfredo Ramos, Macayepo, 2017)

\section{Chengue, Ovejas (Sucre)}

En guerra uno se prepara, es una zona que estaba vuelta guerra en el momento, una zona donde estaba la guerrilla, una zona donde estaban los paramilitares, una zona donde todos estaban en contra de las comunidades. (Alejandro Oviedo, Chengue, 2017) 
Alguna vez Chengue lo tuvo todo, vivió en paz, vivió tranquilo, Según Alejandro Meza, alguna vez fue la columna vertebral del municipio de Ovejas en la parte noroccidental, era un corregimiento de agricultores que tenía un desarrollo total, ahí estaba la gente inteligente, estaban los profesionales, un pueblo que tenía aproximadamente 600 personas, 30 maestros, tenía médicos, tenía abogados.

Infortunadamente, el corregimiento del Chengue fue un corredor muy importante dentro de la cordillera que permeaba esta subregión, al igual que el resto de poblaciones de Montes de María tuvo presencia de los grupos armados ilegales. La presencia de la guerrilla fue la que más permeó la cotidianidad de los habitantes de la región.

La relación no era una relación buena porque la guerrilla se volvió bastante contraria a todos, pero es la que está en la zona, entonces que hace la gente en ese momento, la gente no puede hacer nada, la gente no se puede torcer con ellos ¿por qué? Porque está buscando la muerte. (Alejandro Oviedo, Chengue, 2017)

Sin embargo, y retomando lo que la introducción del presente apartado señalaba, las particularidades históricas, circunstanciales y territoriales de este corregimiento del municipio de Ovejas lo convirtieron en un asentamiento de la guerrilla, sin que esto significara en ningún momento que se pudiera considerar como un pueblo guerrillero, como se planteaba en la estigmatización que los mismos grupos ilegales propiciaban entre los pobladores de la región, lo cual junto a las difíciles condiciones para operar que tuvieron que enfrentar las Fuerzas Militares durante esos años, llevó a los habitantes de este territorio a vivir al margen de las voluntades de grupos guerrilleros quienes controlaban a la población civil, invadiendo los espacios sociales en todas las esferas posibles, lo cual lo convirtió en un objetivo para el Bloque Héroes de los Montes de María.

En Chengue hubo una masacre de lesa humanidad, una masacre bárbara donde hubo 27 muertos, los paramilitares entraron al pueblo e hicieron una moronda bastante exagerada, la gente se sorprendió porque fue una masacre fuerte en un pueblo pequeño, nosotros vivimos eso, es que lo pudimos palpar porque estábamos allá. 
Ellos llegaron como a las 4:30 de la mañana, llegaron a unas casas, llamaron a las personas, llegaron a la parte norte, es decir la parte de arriba, llegaron a la plaza, ahí reunieron a la gente, para reunirlos les dijeron que iban a pasar a todo el mundo por el computador, que estaba detrás de una casa, ellos decían "todos pasa allá detrás por el computador y si encontramos algo malo pues lo arreglamos de una vez". Allá los mataban con mola, venían a buscar otro, y así fueron matando y matando y matando hasta llegar a 27. [...] ellos no venían con lista ni nada, eso dijeron ellos pero no era verdad. (Alejandro Oviedo, Chengue, 2017)

Hubo 27 muertos, sin embargo pudieron ser más, la población no se dio cuenta de la masacre mientras ocurría, sabían que sucedía algo extraño, sin embargo, los asesinatos se daban detrás de una casa que quedaba junto a la plaza, no se oyeron disparos durante la masacre, las personas sin saberlo eran llamadas y acudían al llamado ignorando las repercusiones de la situación que se estaba desarrollando. Según los testimonios analizados, fueron los gritos de uno de los pobladores, quien al llegar atrás de aquella casa y al percatarse de lo que estaba sucediendo empezó a gritar, con lo cual le dio una oportunidad al resto de la población para huir de esta fila del terror. Sin embargo, era demasiado tarde, pues ya se habían robado 27 vidas, los hombres que murieron en el marco de esa masacre fueron campesinos, gente humilde, niños, personas mayores, no combatientes de la guerrilla, ni militantes.

Eran hombres ya de edad, hombres que tenían 60 años, 50 años, ahí no mataron a la guerrilla. Siempre el malo es más preciso para huir que el bueno. El caso de Chengue es un caso lamentable porque murieron personas inocentes, [...] por ejemplo Andrés Meriño, un señor que tenía como 7 hijos, al mayor se lo mataron ahí, era un tipo lejos de guerra, eran agricultores. [...] Le podría mentar a otra persona, un niño, un muchacho joven que estaba enfermo, ¿qué podría hacer una persona enferma? (Alejandro Oviedo, Chengue, 2017) 
La población buscó los medios para llevar a cabo el levantamiento de cadáveres de la escena del crimen. A las 7 de la mañana, a diferencia de otras masacres, en Chengue ya se sabía quiénes eran todas y cada una de las víctimas, pues las cercanas relaciones entre los pobladores facilitaron su identificación.

Tras esto, y al igual que en Macayepo, la población entera se desplazó, huyendo de la violencia, la muerte y la intranquilidad. Sin embargo, después de tres meses la gente tuvo que volver otra vez, pues allá tenían sus fincas, medios de producción para su superviviencia. A pesar de las esperanzas y esfuerzos de la población por recuperar lo que se había perdido en la guerra, con su regreso, las pérdidas materiales implicaron un gran esfuerzo por recuperarla, pues los perpetradores incendiaron todo el pueblo, todas las casas de palma y madera quedaron en cenizas dejando solo en pie la mitad de casas que estaban construidas con cemento y ladrillo.

La guerra dejó en el Chengue una pobreza absoluta, pues después de la masacre la inversión y atención del Estado se han quedado cortas respecto a las necesidades de una población entera para asegurar su calidad de vida y sus condiciones mínimas para el desarrollo real, pues esta población tuvo que empezar de ceros. En la actualidad, la carretera que da vía única de acceso está en malas condiciones, cuando llueve el camino se vuelve intransitable y el corregimiento queda aislado.

En este momento le voy a decir que esa zona se vive en una pobreza absoluta, para que le voy a decir, porque yo nunca he tapado eso, y ¿por qué? Porque el Estado no le ha proporcionado ningún beneficio después de la masacre. Tanto es así que todavía cuando llueve no vamos, tanto es así que para ir a Chengue se necesitan veinte mil pesos de transporte, para ir a dar una vuelta y volver, las vías en peores condiciones, no tiene una escuelita con una profesora, el centro de salud es una casa de familia, o sea imagínate el centro de salud y vive una familia, se ha hablado siempre de, por ejemplo las casas que se van a construir en Chengue, nunca se han podido construir, quemaron treinta casas, el pueblo tenía sesenta y seis casas y quemaron treinta, esas treinta casas nunca las han pido hacer [...]. (Alejandro Oviedo, Chengue, 2017) 


\title{
Chalán (Sucre)
}

\begin{abstract}
A El Chalan lo conocieron por medio del burro bomba. Un hecho que al mundo asombra y que no quiero recordar. Once policías murieron en el momento preciso. En la historia soy conciso y mi mente hoy lo refiera. Desde ahí empezó el suplicio de mi tierra chalanera. (Adolfo Álvarez, Chalán, 2017)
\end{abstract}

El burro bomba en el año 1996 fue considerado como el detonante del conflicto en la región de Chalán, pues a partir de ese momento, al ser un ataque directo contra la Policía, la Fuerza Pública al no contar con medios suficientes y al ser un blanco directo de las guerrillas que asediaban el territorio, tuvieron que retirarse de la población.

[...] desde ahí el Estado abandonó todo esto, aquí no metió más policía ni soldados, todo esto lo abandonó. Después se metieron los paracos, mataron, aquí hubo una masacre, se fueron, se desterró el ejército, policía y todo. Duraron como tres años en que no estuvieron, solo venían, hacían el cruce por aquí y volvían y regresaban. [...] La guerrilla se apoderó del pueblo, entonces como ellos tenían aquí milicianos les avisaban cuando venían los del ejército y se iban mientras pasaban y luego volvían. (Ricardo Díaz, Chalán, 2017)

Esta situación particular, le dio la posibilidad a la guerrilla de alcanzar su objetivo, apoderarse de la población y gobernar sobre ellos, imponiendo sus normas, sus modos de vida y sus castigos. "Era lo que ellos dijeran, si ellos decían hay una reunión allá, y uno no iban, lo buscaban a uno a las 4 de la tarde y lo sacaban para ir [...] ellos lo trataban a uno bien. (Ricardo Díaz, Chalán, 2017)

Tras dos años de una baja incidencia y presencia en el territorio, las Fuerzas Militares volvieron con el fin de establecerse y recuperar la soberanía del territorio controlado para entonces por miembros de las FARC. La presencia y accionar de la Armada Nacional logró la 
recuperación del casco urbano, mientras las guerrillas mantuvieron sus asentamientos en el monte, lo cual implicó una época de enfrentamientos contantes de la Fuerza Pública contra las guerrillas. Un contexto en el que la población civil se vio afectada por la intensidad de los combates.

Todos los días a las siete o siente y media de la mañana comenzaba el tiroteo del ejército, del pueblo pa' allá y de la guerrilla hacia el pueblo. Duramos en ese son cuatro años en los que uno no abría las puertas, que uno pasaba encerrado, acostado por ahí en el suelo, no se sabía no quienes lanzaban las granadas. Los tiros los "desfondaban" las casas, y hubo mucha gente, como cuatro señores, que murieron, señores ya de edad del susto. [...] Y aquí todo el mundo quedó muy afectado por la guerra. Aquí uno oía reventar "traque traque" y no encontraba uno donde pararse, tenía que buscar una casa hubo cuatro años que a las 506 de la tarde encerrado y ahí no se asomaba uno pa' ni se oía lo que pasaba afuera. (Ricardo Díaz, Chalán, 2017)

La población tuvo que convivir simultáneamente con miembros de la guerrilla y de las Fuerzas Militares durante cuatro años, lo cual los llevó de manera casi obligada a generar algunas relaciones sociales con miembros del Grupo armado ilegal y de las Fuerzas del Estado. "Aquí una hija mía que estuvo amenazada con la guerrilla, vivía con un soldado como eso, la amenazaron de muerte, la iban a matar, los milicianos me lo decían a mí, me decían, los van a matar" (Ricardo Díaz, Chalán, 2017).

Según diversos testimonios, la expulsión de la guerrilla de la zona, tras el accionar constante de la Armada Nacional, se dio en el 2002. A partir del año 2006 las Fuerzas Militares implementaron en la región la agudización de la persecución sistemática de las guerrillas por medio del Plan de Recuperación de los Montes de María, así como hubo un cambio en las dinámicas de relaciones con la población civil, en medio de lo cual se reestablecieron relaciones y el cual resultó en una eliminación del conflicto armado al cabo de media década. 


\section{El estigma y la soledad de Montes de María}

Figura IV-4. El silencio

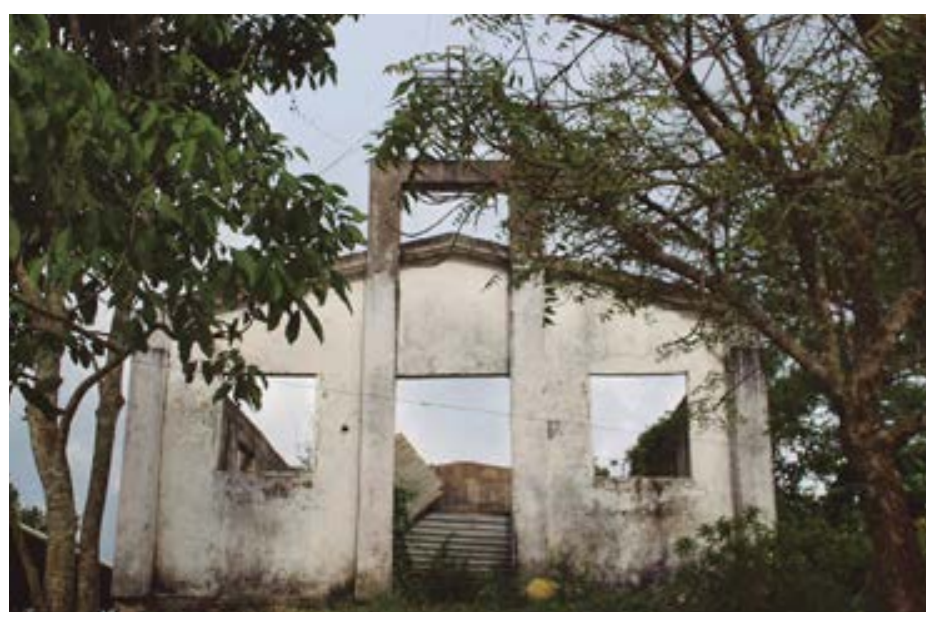

Fotografía de María del Mar Martínez, Cerro La Cansona, Diciembre de 2017.

Es evidente hasta ahora que uno de los factores más importantes para los grupos armados fue el control de las poblaciones civiles, así mismo, sus métodos de control y repertorios de violencia para lograrlo variaron según los contextos, y las dinámicas del conflicto se fueron estableciendo dentro de los habitantes del territorio de maneras distintivas, pero en todos los casos se desdibujaron las voluntades y posibilidades de elección ante sus propios destinos, encarnándose en la supresión de la libertad de manera física y psicológica, lo cual implicó no solo estar a la merced de los actores armados, sino además, una transformación de la realidad en la cual las concepciones frente al mundo y al propio territorio se modificaron en medio de la crisis y el desajuste emocional generalizado.

Es en este momento, donde juega un papel fundamental la estigmatización de las poblaciones, la cual se hizo presente de alguna manera en todas las narrativas analizadas en medio del presente contexto, y su consecuencia más directa, el aislamiento y la rivalidad, trascendiendo la guerra a las mentes de los pobladores y ocasionando mayores índices de segregación, violencia y vulnerabilidad en las zonas más estigmatizadas. 
Es este el caso de Chengue, El Chalán, El Salado "tierras de guerrilleros", Macayepo "tierra de paracos", San Onofre "la casa de los paracos", estas estigmatizaciones que iniciaron como una estrategia de aislamiento y control de los grupos armados ilegales en las poblaciones se expandieron dentro de los imaginarios colectivos y ante todo permearon en gran parte las mismas instituciones estatales, revictimizando a los territorios y exponiéndolos cada vez más a actos atroces contra sus pobladores.

No obstante, esto no fue un fenómeno que solo se dio entre una población y otra, a su vez el control de los grupos sobre los territorios llevó a un deterioro en las relaciones civiles y vecinales en los Montes de María, cada quien estaba por su cuenta, hubo una pérdida generalizada de la confianza en el otro y eso hacía imposible que se estableciera una concepción de comunidad, haciendo que fuera cada familia una unidad débil y pequeña, enfrentándose al conflicto armado. Estas serían condiciones particularmente beneficiosas para la perpetuación de la guerra, pues los pobladores al sentirse expuestos y solos veían como su única opción subyugarse ante las dinámicas propuestas por los grupos armados ilegales.

Ese mutismo que se cernió en toda la población donde la vieja Emilia le rezaba al perro pa que ladrara [...] el temor era tan grande, sobre todo cuando llegaron los grupos de ultraderecha, que nadie decía absolutamente nada, el que dijera ya era un pecado mortal.

Todo fue permeado desde las instancias gubernamentales, religiosas, la plaza pública, la tienda, la esquina, es decir, uno no sabía el interlocutor de qué lado estaba, entonces mejor no abordar ningún tema, el saludo de buenos días era, ¡ah! Jugó en ocho la bolita de Doña Enlise, es decir, la gente adquiere algunas estructuras semánticas como mecanismo de defensa para mitigar el efecto de la procesión que lleva por dentro. Entonces el compadrazgo hasta se perdió, porque uno no sabía el informante era a fin a que, porque es que allá había de todo [...] inclusive hacer un favor era pecaminoso. (Moisés Morantes, Carmen de Bolívar, 2017) 
La segregación y estigmatización llegaron al punto de justificar en algunos momentos hechos de violencia contra diferentes tipos de poblaciones, las mujeres que eran abusadas sexualmente fueron una población que, en medio del machismo y las dinámicas que generó la estigmatización, se vieron opacadas e incluso se llegó a pensar que no existía violencia en tal acto.

Nosotras empezamos a desconfiar de las instituciones, porque empezaban a decir, no es que en san Onofre hay tres o cuatro casitos de violencia sexual, ahí se violó a la vende galletas, a la fulana y esta, a las otras esas peladas eran bandidas y por eso los paramilitares las violaron. [...]. (Norlis Judith, San Onofre, 2017)

En consecuencia, la estigmatización y la segregación fueron un arma de guerra, que, sin pretenderlo, también tomaron los civiles para protegerse a sí mismos en un contexto incierto, inestable, violento y cambiante, donde cada día la historia del muerto se iba volviendo más cotidiana y parecida a la anterior, y en la que los ataques en su contra se hicieron parte del día a día, sin tener más opción que guardarse el dolor y seguir adelante.

\section{El legado de la guerra}

Figura IV-5. Memorias

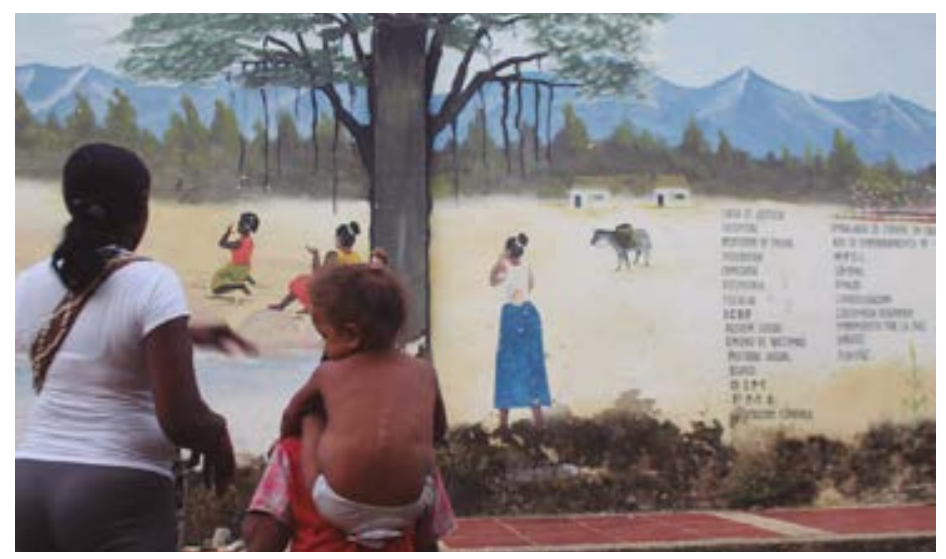

Fotografía de María del Mar Martínez, San Onofre, Diciembre de 2017. 
Es imposible pensar que al terminar la guerra, al retornar a sus pueblos, al irse los grupos armados de los Montes de María, la vida volvió a ser la misma. Las cicatrices de las guerras son evidentes en los ojos de cada persona que la vivió y en las formas de actuar de quienes nacieron en ellas. Es lamentable señalar que pese al fin de los fusiles, y a la victoria militar lograda por el Estado a través de la Armada Nacional, aún no ha terminado el sufrimiento y el dolor, y que todas las formas de violencia desatadas ha afectado las semillas de esperanza dentro de la sociedad, los niños y los jóvenes.

Resulta un común denominador en todos los discursos, la preocupación por las juventudes de hoy en día, y es reverberante el tema del microtráfico y la deserción estudiantil. Podríamos decir que se trata de las nuevas generaciones que vienen, así que son los nuevos tiempos, pero los nuevos tiempos están absolutamente ligados a una historia y a un pasado violento que dejó un legado.

Hay mucho temor acá, o sea, estamos en el posconflicto, pero estamos en los mismos casos que vivimos, o sea, con otra vestimenta, o con otra razón social, no sé, porque vemos muchos movimientos en el municipio, tenemos temor, anteriormente usted veía al ejército, a los paramilitares, a la guerrilla o a las águilas negras y usted los identificaba, pero hoy en día usted no identifica, hoy se opera con los jóvenes desde las casas, no tienen que estar en una casa conformada o establecida porque desde cada casa de los jóvenes tienen sus redes. A mí me da, sinceramente a las 7 de la noche yo ya tengo la puerta de mi casa cerrada porque hay mucha zozobra, mucho miedo, porque uno no sabe quién es quién o en qué momento le pueden hacer a uno algo [...] estamos en unos barrios en cuanto al tema de drogadicción, esto está perdido en la drogadicción, antes uno encontraba muchachos que fumaban desde los 18 años en adelante, ahora uno encuentra en los barrios más vulnerables niños desde los 10 años metidos en la droga, perdidos en la droga. (Norlis Judith, San Onofre, 2017)

La construcción de una comunidad, que paso a paso abonó todos sus esfuerzos para dejar atrás y reconstruir sus sueños, tuvo un vacío muy grande en cuanto a la reparación psicosocial a tiempo dentro de 
los municipios. La construcción de nuevas realidades, poder reescribir sobre una historia de sangre implica una atención a los traumas que dejó la guerra, eliminar las semillas de violencia que alguna vez se sembraron en los corazones de quienes la padecieron, para que a partir de esto se construya una nueva forma de vivir y así tener unas garantías claras de no repetición.

Acá hay un trabajo muy grande por hacer y es con las mujeres, porque la mujer es el eje del núcleo familiar y si la mujer está afectada, afecta el núcleo familiar, por eso hoy el incide de que los niños de la violencia, los niños que nacieron en ese episodio de la violencia, hoy son los niños el problema social, por eso, no hubo atención para estas mujeres, a estas mujeres no les brindaron cariño no le brindaron amor a sus hijos, y hoy estamos viviendo de que al niño la mamá no lo puede aguantar, la institución no lo puede aguantar [...]. (Norlis Judith, San Onofre, 2017)

Las heridas de la guerra, las cicatrices, no solo las llevan aquelos que en algún momento de sus vidas fueron violentados por grupos armados ilegales; dentro de las dinámicas del conflicto, estas generan una inestabilidad emocional y unas consecuencias a largo plazo.

Es importante hablar en este punto de la transformación que tuvo la sociedad montemariana de ser una comunidad de agricultores a convertirse en una población que tuvo que adaptarse a la guerra y que tuvo que prestar sus hijos forzosamente para que "protegieran" el territorio desde alguno de los bandos.

La guerra también trajo consecuencias para los miembros de la Fuerza Pública, quienes padecieron toda la inclemencia y dolor de la guerra.

Yo vivía con estrés y zozobra permanentemente a través de las informaciones que nos daban porque la red de inteligencia siempre nos estaban avisando o informando, miren que se interceptó la comunicación y les van a dar, miren, que por tal lado vieron personal en la carretera, andábamos con ese estrés de miren que nos van a dar Dios mío que no nos pase nada, cuando íbamos en la carretera más que todo que eran los momentos más críticos. 
Llegué en la noche y al día siguiente ya me estaban echando para los Montes de María, uno llega loco no sabe qué es esto [...] fuimos a parar por aquel lado de Chalán, y no acababa de llegar cuando eso era plomo, y uno como soldadito principado no sabía, a pegársele a uno antiguo a la riata. [...] Fueron tiempos tan duros que nosotros llegábamos con los miembros de la Infantería de Marina en representación del Estado y esas poblaciones no nos daban ni agua. (Fabio del Cristo Baldovino, Infante de Marina profesional retirado, 2017)

Pese al entrenamiento militar y a la capacidad de adaptarse a contextos extremos, también generaron traumas y miedos, y en muchos casos las consecuencias de su permanencia en la guerra les causaron igualmente daños físicos irreparables que hoy en día les recuerdan los años de conflicto y que hoy en día afectan su cotidianidad.

Yo fui víctima de balones bombas, tipo explosivo artesanal de alto impacto, saliendo del Carmen para Zambrano, a mí me volaron toda la masa muscular y me dieron cuatro tiros en la pierna derecha, el dedo me lo volaron y tengo 20 esquirlas aquí en el pecho en el lado derecho. (Sargento Casarrubia, miembro de la ARC, 2017)

Cuando íbamos subiendo tuve la desfortuna o un episodio desafortunado de accionar una mina antipersona, esa mina antipersona me voló en seguida mi pierna izquierda [...] ahí cayeron dos compañeros más míos, no sobrevivieron. (Fabio del Cristo Baldovino, infante de marina profesional retirado, 2017)

Del mismo modo, a nivel psicosocial las afecciones y repercusiones de la guerra se reflejaban en el permanente estado de alerta o algunas afecciones a nivel psicológico, los cuales influyen de alguna $\mathrm{u}$ otra manera dentro de los hombres que combaten en las Fuerzas Militares. 
Me cercenaron parte de mi vida, me cambio totalmente [...] desde ahí todos los octubres serán negros [...] desde ahí quedo marcado, y fueron dos vidas, antes de y después de eso. (Fabio del Cristo Baldovino, infante de Marina profesional retirado, 2017)

Yo he quedado con secuelas de eso psicológicamente, estoy afectado a cualquier explosión o tiro o bulla que haga, ya estoy nervioso, quiero es irme, perderme de ahí porque ya siento que me van a buscar y que me van a encontrar. (Sargento Casarrubia, miembro de la ARC, 2017)

Es imposible negar la historia, borrar las heridas de una guerra en absoluto, sin embargo, es también imposible no ver los esfuerzos que toda una población ha hecho para seguir adelante, para cambiar sus dinámicas para no volver a vivir la violencia. Este concepto de resiliencia, a través del cual no solo se supera un momento traumático sino que además ese momento es el que da más fortaleza y se convierte en la catapulta para emprender con más fervor esos sueños.

\section{Recuperando la montaña}

Figura IV-6. Vigilia

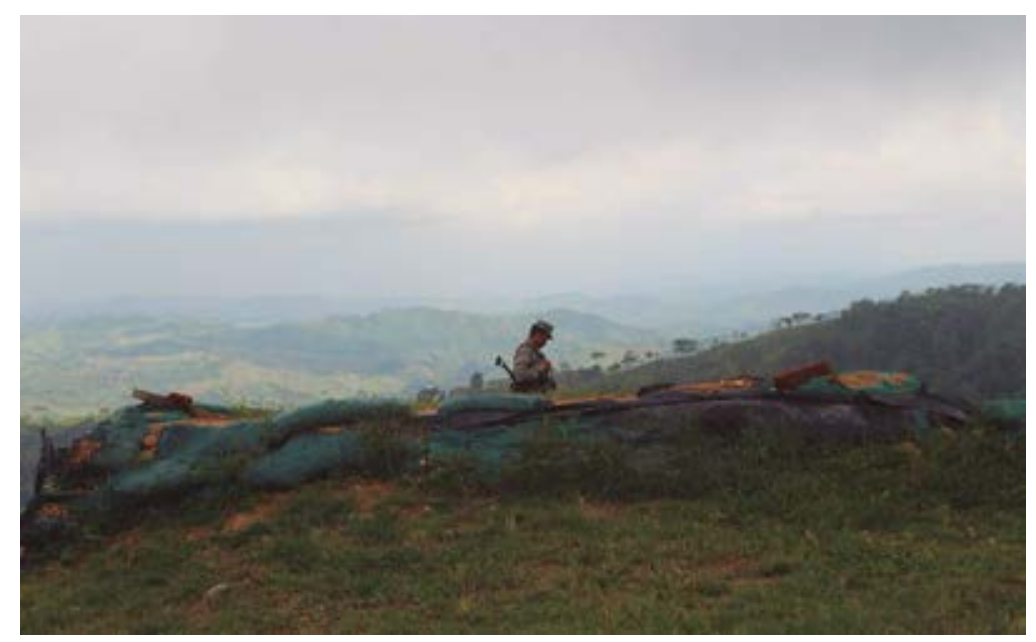

Fotografía de María del Mar Martínez, Cerro La Cansona, Diciembre de 2017. 
A partir del año 2002 con la llegada de la Política de Seguridad Democrática, tal y como se planteó en el capítulo sobre dinámicas del conflicto, el Gobierno instauró un plan de recuperación y consolidación en los Montes de María, en medio de lo cual la transformación de las estrategias para atacar los grupos al margen de la ley tuvieron muchos cambios. Uno de los más importantes al cual hace referencia el presente apartado es la recuperación de la población civil, la cual, durante un periodo del conflicto, perdió confianza en las instituciones del Estado, por la coacción ejercida por los grupos armados ilegales.

Para Yordaniel Rivero, ex combatiente de las FARC, esa fue la estrategia más contundente que le permitió al Estado acabar con las guerrillas en Montes de María.

Las montañas de la guerrilla era la población civil, no era el monte porque la guerrilla sin la población civil no tenía nada. Entonces el Gobierno anteriormente llegaba a las partes y maltrataba a la población civil, no sabía llegarle, entonces todo el mundo se iba a la parte de la guerrilla que si tenía una estrategia y era que trataba al campesino bien. Cuando el Gobierno detectó eso que dijo tenemos que coger con la población y tenerla del lado de nosotros. Cuando el Gobierno empezó a trabajar con la población primero y no el grupo delincuente, fue cuando le dieron el golpe a la guerrilla, cpor qué? Porque ya la guerrilla perdió las montañas, las tenía la Infantería, por eso acabaron la guerrilla. (Yordaniel Rivero, desmovilizado de las FARC-EP, 2018)

Este cambio de estrategia por parte de la Fuerza Pública en medio del conflicto también se ve reflejado dentro de las narrativas de los habitantes de los Montes de María, los cuales reconocen una transición en la cual hubo una reintegración de la sociedad civil acompañada con transformaciones en las dinámicas relacionales de los pobladores tanto con la Fuerza Pública y más tarde entre ellos, reestableciendo el tejido social por medio de una evolución en la percepción de seguridad, cercanía y empatía con las comunidades, haciéndose parte de ellas. 
Cuando empezó esta Casa del Almirante que vinimos a la inauguración, el Coronel que estaba al mando le dijo a las víctimas, porque la celebraron con todas las víctimas del municipio, dijo que ellos estaban a la orden y fuimos aprovechando esos espacios y se construyeron aquí las ollas comunitarias con ellos, íbamos y hacíamos limpieza de los barrios [...]. (Norlis Judith Herrera, San Onofre, 2017)

La seguridad es muy importante, y yo creo que nosotros en los territorios de Montes de María estamos confiando de nuevo en nuestra Fuerza Pública, porque también ellos tienen que renovarse y saber que estamos en otras épocas, no está pasando en otros lugares de Colombia donde todavía la guerra está viva, pero aquí estamos en transición hacia la paz y lo que tenemos que generar desde todos es la confianza en lo local, regional y nacional porque tenemos que estar unidos. (Soraya Bayuelo, Carmen de Bolívar, 2017)

La búsqueda de la unidad y recuperación de las relaciones también se pudo desarrollar con el mejoramiento de las redes de comunicación entre la Fuerza Pública y la población; por ejemplo, el programa de incorporación de Infantes de Marina de mi Pueblo constituyó otro factor fundamental a través del cual las instituciones militares lograron acercarse a las poblaciones, pues a través de esto se unían a la Armada Nacional, infantes de Marina campesinos, miembros de las mismas comunidades, lo cual hacía desarrollar la confianza de las comunidades, pues quienes hacen parte de la Infantería de Marina son los hijos, hermanos y amigos de los habitantes de los Montes de María. 


\section{Arte y cultura, la cura de los Montes heridos}

Figura IV-7. La Gaita

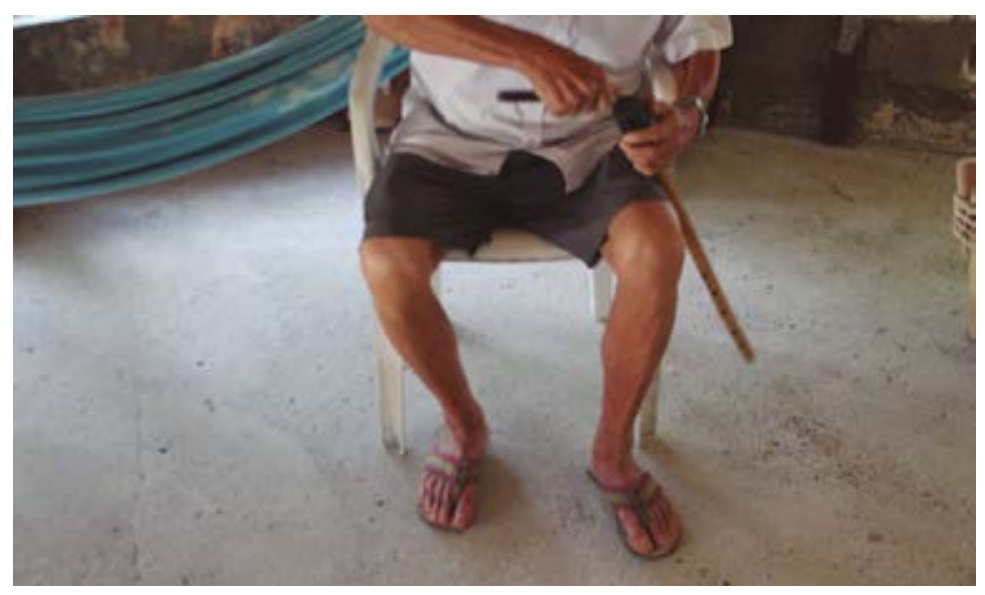

Fotografía de María del Mar Martínez, Cerro La Cansona, Diciembre de 2017.

Una de las hebras más importantes dentro del tejido social en los Montes de María, un hilo trasversal que caracteriza y une a los rincones de la región, es la tradición artística y cultural, la cual se construye como un tesoro invaluable guardado en las memorias de todos los montemarianos cuya semilla no dejó de nutrirse y cuya fortaleza y diversidad la convirtieron en un centro de expresión y catarsis, dentro del cual se exteriorizaron los sentimientos y necesidades de la población.

La región de los Montes de María es un lugar de contrastes ubicada en la zona caribeña de Colombia; es un sitio lleno de riquezas culturales y étnicas: Es negro, indígena y blanco; es mestizo, pero de igual manera es zambo y mulato... somos raza cósmica. Es tierra de gaitas, pitos y tambores, emanación natural de gritos de monte, décimas, zafras y cantos de vaquería; un lugar donde es posible contagiarse con los sonidos de guitarra, dulzainas, acordeones y bandas de viento; un espacio para dejarse atraer por las antiquísimas ocarinas, los caracoles llamadores, el carángano y la hojita 
melódica. Todos reunidos en una complicidad para dar lugar a un sinnúmero de géneros y ritmos musicales [...]. (Morante y Teherán, 2011, p. 100)

Según cuentan Morantes y Teherán, pobladores de los Montes de María y personas apasionadas por la reconstrucción de la memoria histórica de la subregión, durante los años de conflicto armado, los festivales en los diferentes municipios se convirtieron en escenarios de protesta pacífica, donde a modo de prosas, melodías, ritmos y poemas, la población podía liberar sus pensamientos inconformidades y tristezas que debían ser calladas en la vida cotidiana. A pesar de los múltiples intentos de los grupos por anular estas expresiones de alegría y unión del pueblo, al final la sangre artística de estas tierras luchó por mantener los espacios escasos para hacer más llevaderos los momentos más críticos de su historia.

[...] la gente de los Montes de María que atestiguó y sufrió en sus propias carnes un conflicto violento incesante tan intenso, acogió un hecho esencial de hacer música: la música entendida como comunicación humana y como construcción cultural que tiende en última instancia a beber del manantial del optimismo del espíritu humano. (Morante y Teherán, 2011, p. 106)

San Jacinto, Carmen de Bolívar y Ovejas son algunos de los municipios que fueron testigos de esta resistencia de la sociedad a olvidarse de sus orígenes, sus habitantes encontraron en el arte y la cultura un punto de fuga en medio de la guerra y la violencia.

[...] En unos pueblos nos levantaron a plomo, nadie podía salir después de las seis de la tarde, pero yo decía, ¿por qué no vamos a salir? Salíamos con tambores, gaitas, y a tocárselo en la plaza, entonces inventábamos la noche montemariana para alejar el miedo, entonces, llevábamos todos los artistas, de 14 pueblos, pero de los mismos pueblos, 14 de gaitas, acordeoneros, hacíamos cosas bien bonitas, pero en uno de esos pueblos, San Juan y Ovejas quedó esa plaza sola, entonces yo pensaba que no era posible que pasara eso, entonces les dije 
a los del equipo trabajo que volviéramos, como a la hora se llenó otra vez la plaza, y ahí amanecimos tocando y así pasó en San Juan también. (Jorge Quiroz, San Jacinto, 2017)

Así mismo, el arte, la cultura, la tradición y la memoria se convirtieron en un proceso de reconstrucción del tejido social en sí mismo, por lo cual este es un elemento que es ineludible hoy en día en todos los procesos comunitarios dentro de los diferentes municipios que conforman los Montes de María. Este componente se ha convertido en una herramienta de expresión psicosocial en medio de la cual las poblaciones han recuperado relaciones de unión, confianza y compadrazgo, pues estos espacios de expresión se convierten en una excusa para ser libres y felices, y comprender ese elemento común de identidad en las cuales se resinifican a sí mismo como acreedores de un tesoro inmaterial, la alegría de la música la danza y el arte en general.

Descubrimos que trabajar con los niños y con los jóvenes era divino porque nos Dios cuenta también que los niños y los jóvenes no tenían esperanza. Aquí en el colectivo cuando venían los niños uno los encontraba llorando en un rincón y les decía “¿tú por qué lloras?”, “porque me estoy acordando de mi papá, - ¿y qué le pasó a tu papá?, -me lo mataron, - ¿y quién era tu papá?, -Era fulano de tal-; y ahí uno entendía que los niños que venían acá estaban destrozados y con una falta de ayuda psicosocial, entonces a punta de cámaras, de dibujos, de coger los micrófonos y usar las pinturas fuimos haciendo ese proceso de recuperación psicosocial, pero también trabajamos la memoria de lo que pasaba. (Soraya Bayuelo, Carmen de Bolívar, 2017) 


\section{Referencias}

Baer, A. (2010). La memoria social. Breve guía para perplejos. En: Zamora, J. A. y Sucasas, A. (Eds.), Memoria, política, justicia. Madrid: Editorial Trotta.

Caracol Radio. (11 de septiembre de 2011). Caracol Radio. Obtenido de http:// caracol.com.co/radio/2011/09/11/nacional/1315742400_545502.html

Carr, D. (1997). "Narrative and the Real World: An Argument for Continuity”. In: Editor Lewis P. Hinchman and Sandra K. Hinchman, Memory, Identity, Community: The Idea of Narrative in the Human Sciences. SUNY Press. New York.

Castiblanco et al. (2017). Protegiendo el azul, comprendí el rojo de la bandera. Colombia, Universidad Santo Tomás.

Castro, J. (4 de abril de 2012). Desminadas 3 áreas en los Montes de María. El Universal.

CNMH (2009). La tierra en disputa. Colombia: Centro Nacional de Memoria Histórica.

Cincep. Noche y Niebla. (11 de febrero de 2018). Banco de Datos. Programa por la Paz.

Czarniawska, B. (2004). Narratives in Social Science Research. London: SAGE Publications.

Dávila Ladrón de Guevara, A. Salazar, G. y González-Chavarría, A. (2016). El conflicto en contexto. Análisis de 5 regiones colombianas (19982015). Bogotá, Pontificia Universidad Javeriana.

De los Ríos. E., Becerra, C. Oyaga. F, Equipo Ilsa. (2012). Montes de María entre la consolidación de territorio y el acaparamiento de tierras. Aproximación a la situación de Derechos Humanos y del Derecho Internacional Humanitario en la región (2006-2012). Bogotá: Publicaciones Ilsa.

Diálogo. (2010). Desempeño militar en la consolidación colombiana. Diálogo.

García, A., Vega, I., Montero, P., Velázquez, C. y Segrera, Y. (2010). Buenas prácticas para superar el conflicto: casos de los Montes de María. En R. González y A. Mason(Eds.), Colombia y el hemisferiofrente al nuevo orden global (pp. 55-103). Barranquilla: Ediciones Uninorte.

Girón, O. y Vidales, R. (2010). El rol reparador y transformador de la memoria.En:Memoria, silencioy acción psicosocial.Bogotá:Ediciones Cátedra Libre. 
Grupo de Memoria Histórica (2010). La tierra en disputa. Memorias de despojo y resistencia campesina en la Costa Caribe (1960-2010). Informe del Grupo de Memoria Histórica de la Comisión Nacional de Reparación y Reconciliación. CNRR. Taurus. Bogotá.

La Silla Vacía (2011). "Así se concentró la tierra en Montes de María” Recuperado de http://lasillavacia.com/historia/asi-se-concentrola-tierra-en-los-montes-de-maria-25534

Marín et al. (2016). Victorias desde el aire. Bogotá: Editorial Ibáñez.

Morantes Narváez, M. y Teherán Vásquez, P.C. (2011). La tarima como instrumento de resistencia civil en el conflicto armado de los Montes de María en Colombia 1990-2010. Cartagena, Bolívar.

Pinto Borrego, M. E. et al. (2004). El secuestro en Colombia: caracterización y costos económicos. Archivos de Economía. Documento 257. Dirección de Estudios Económicos. Departamento Nacional de Planeación. República de Colombia. 9 de Junio de 2004.

PNUD (2010). Los Montes de María: análisis de la conflictividad. Colombia: Impresol.

Porras, M. (2014). Conflictos, violencias y resistencias en los Montes de María. Un análisis de temporalidad extendida en territorio y conflicto en la Costa Caribe. Bogotá. Odecofi. Pp. 331-386.

Observatorio de Derechos Humanos y DIH (2009). Dinámica espacial del secuestro en Colombia 1996-2007. Vicepresidencia de la República de Colombia. Bogotá.

Observatorio del Caribe. (s.f.). Caracterización de la región Caribe. Recuperado de: http://www.ocaribe.org/region-caribe 
